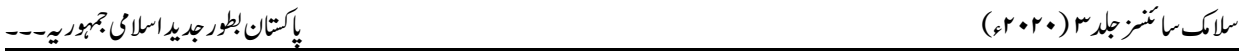

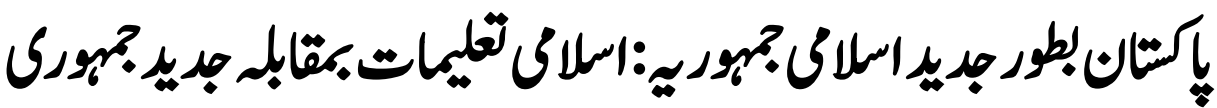

\author{
اصولوضوابط
}

\section{Pakistan as a modern Islamic democracy: The quest between Islamic teachings and modern democratic modes}

عار

\begin{abstract}
:
Democracy is the best form of government in the $21^{\text {st }}$ century and West is not accepted any regime just and trustworthy without it. With this reference all colonial power in general and British Empire in particular emphasized the democratic format in all its colonies before giving them independence. Thus, after the creation of Pakistan every effort was made to bridge the Islamic modes and democratic rules in creating constitution for a newly born Islamic state. Starting from objective resolution to 1973 constitution every effort is made on Islamic, political and legal grounds to achieve the task of modern Islamic democracy. This research paper is an effort to understand the relation of both aspects and explain the future prospects of its achievement.
\end{abstract}

Keywords: sovereign power, political system, rules, Shura, Islamic institution, democracy

$$
\begin{aligned}
& \text { تحارف: }
\end{aligned}
$$

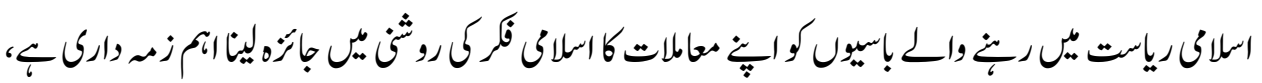

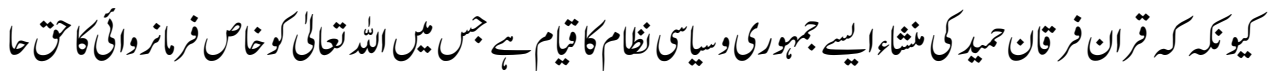

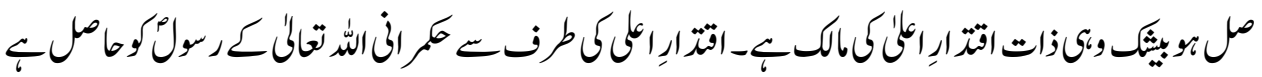

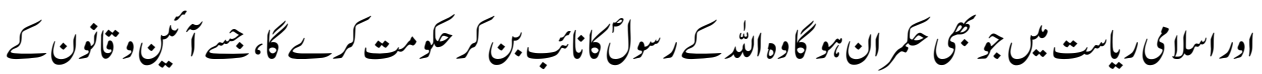

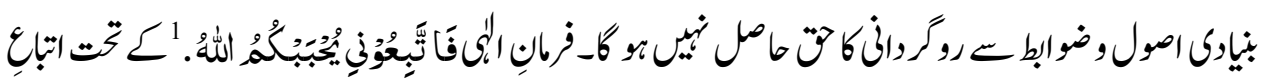

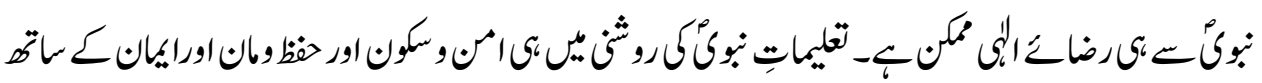

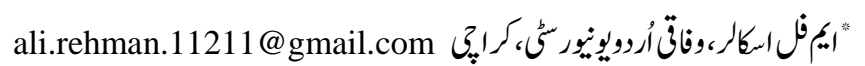




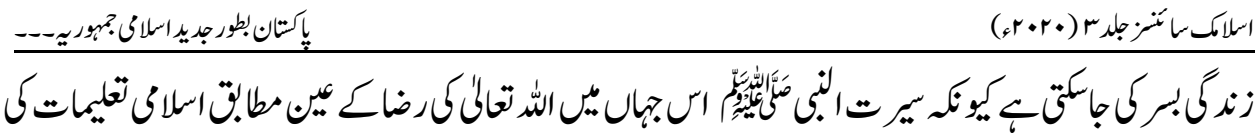

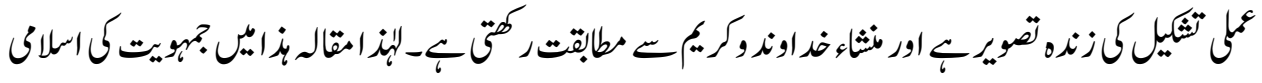

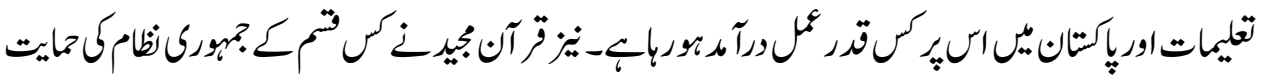

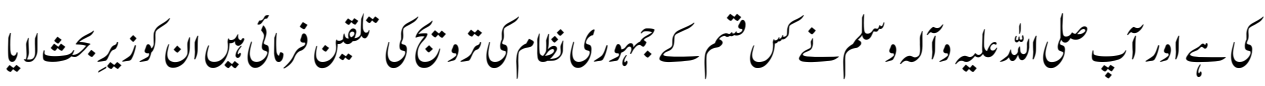

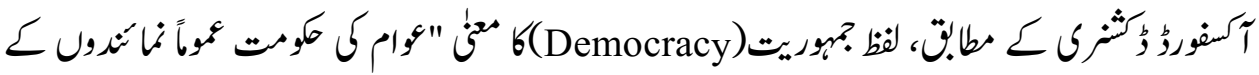

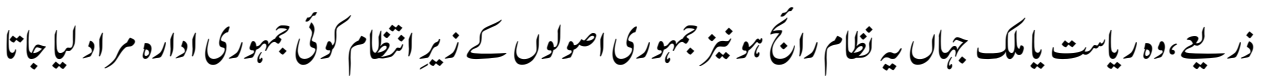

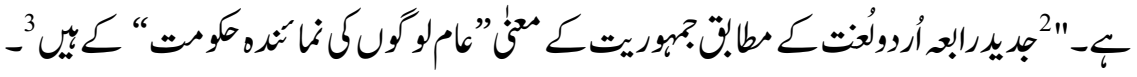

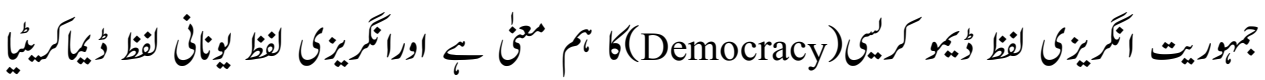
(Democratic)

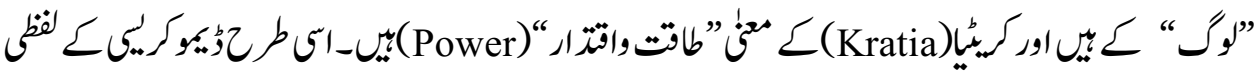

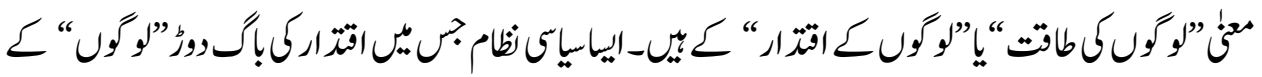

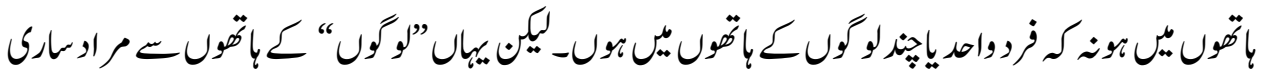

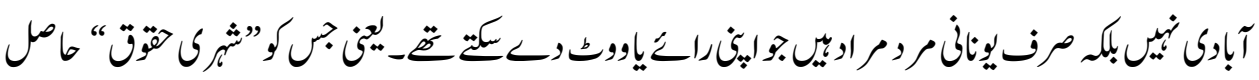

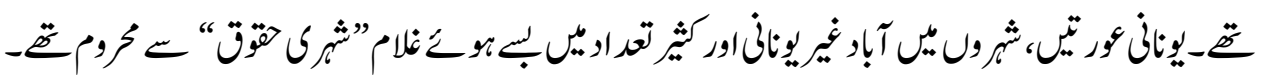

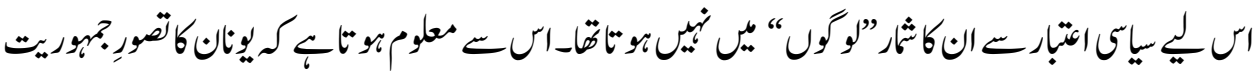

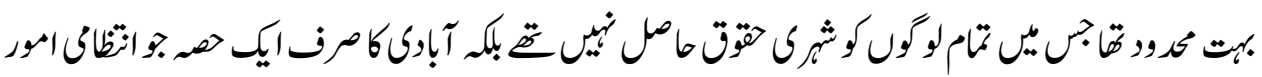

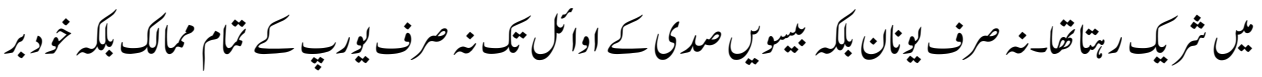

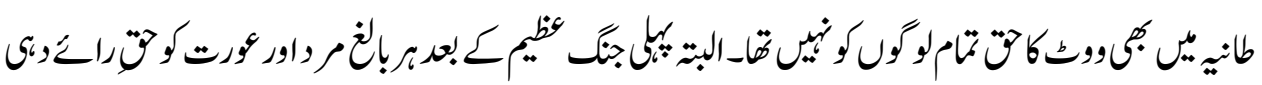

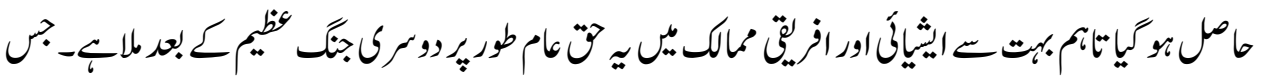

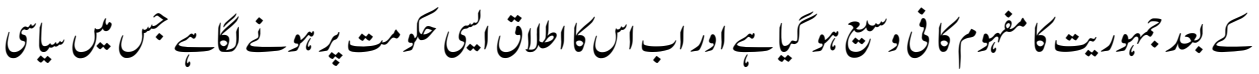

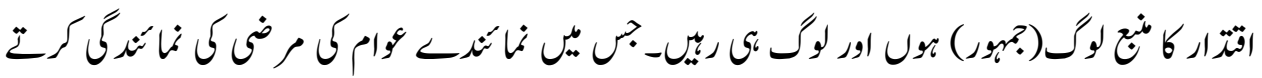

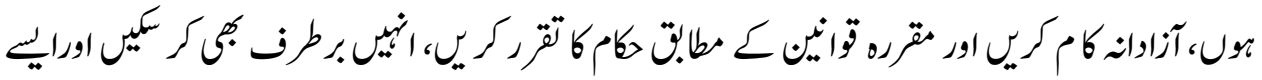

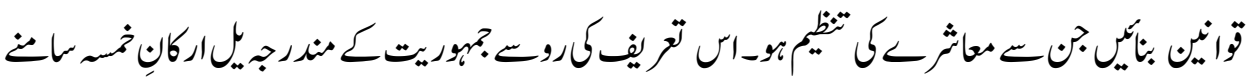




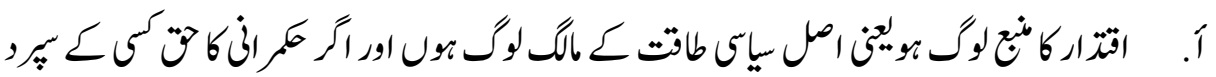

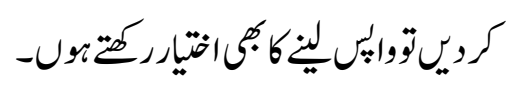

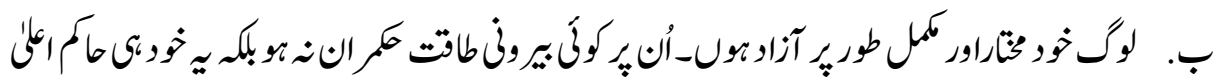

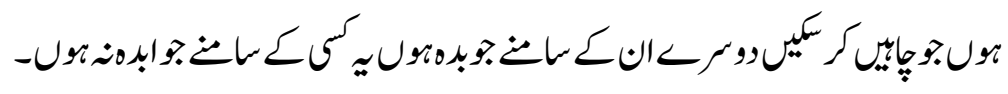

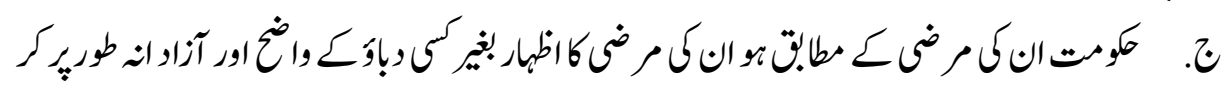

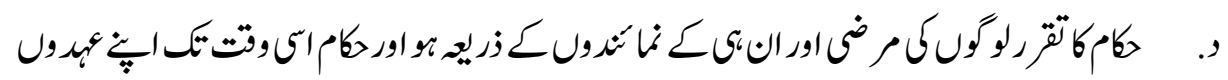

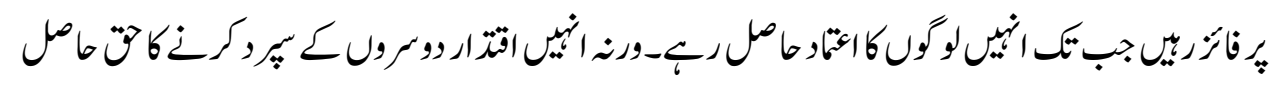

رباور

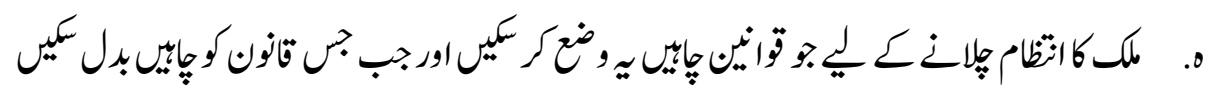

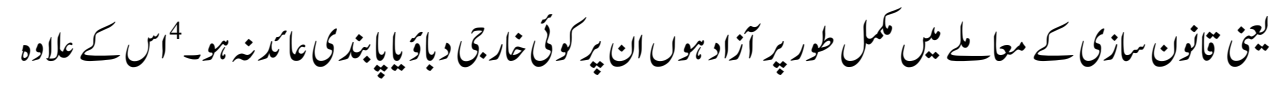

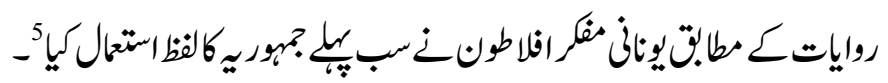

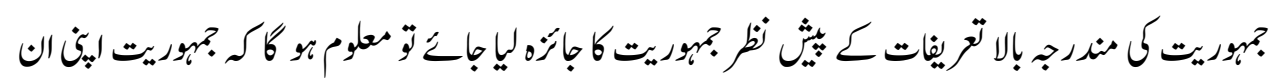

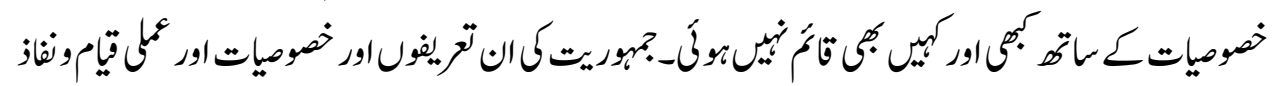

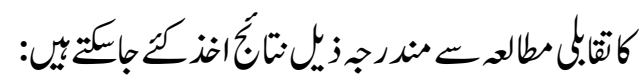

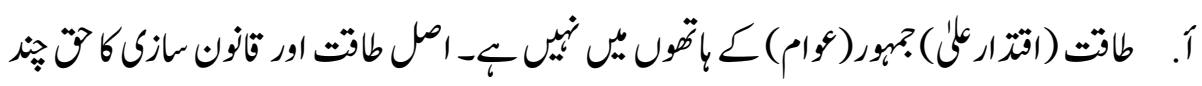

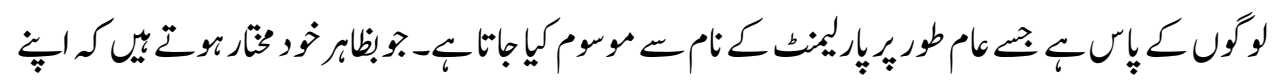

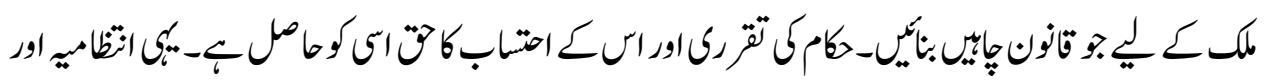

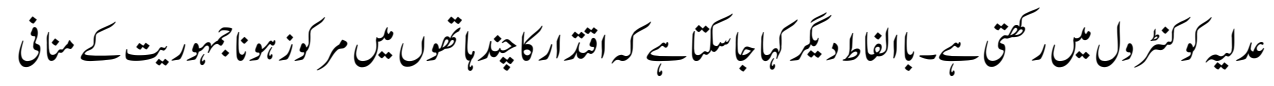

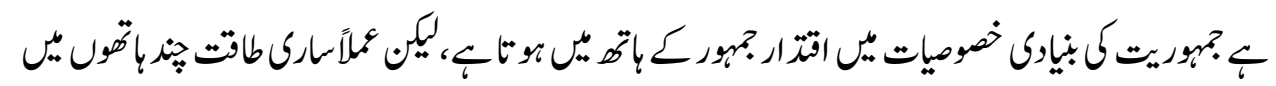

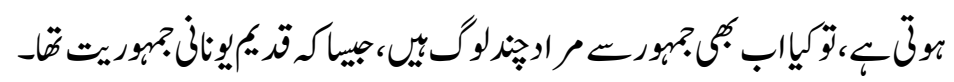

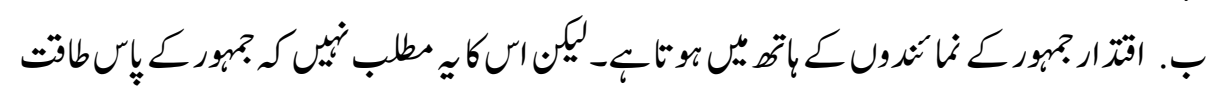

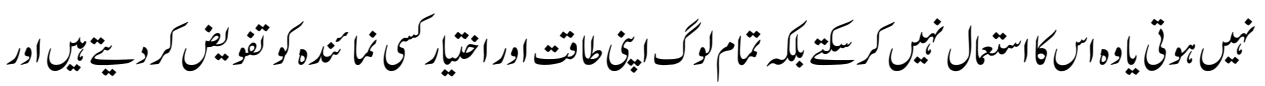




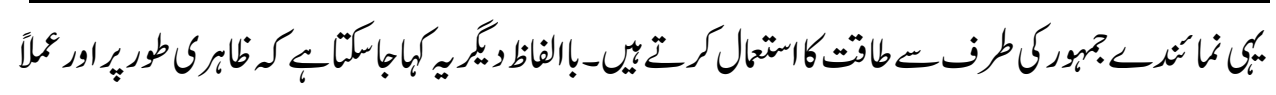

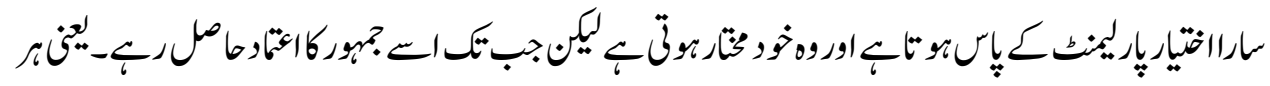

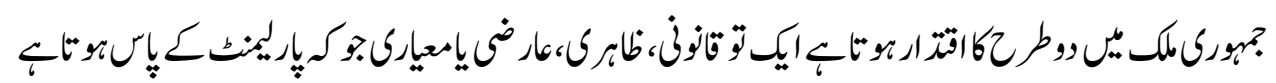

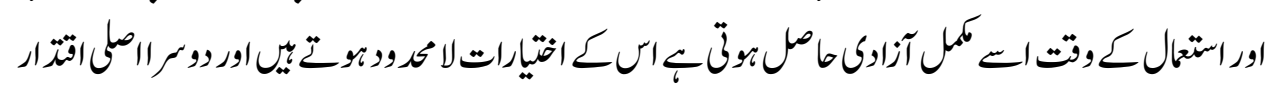

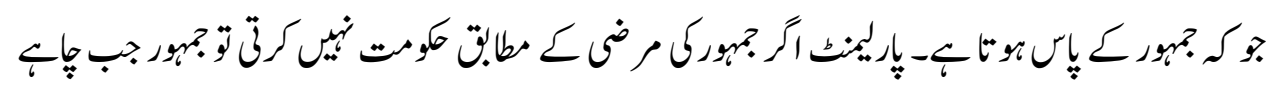

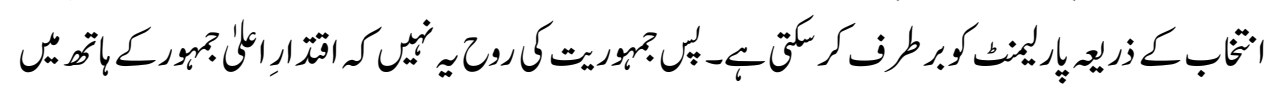

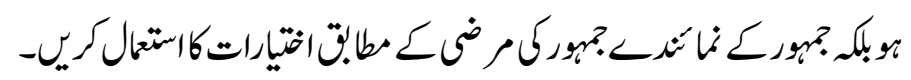

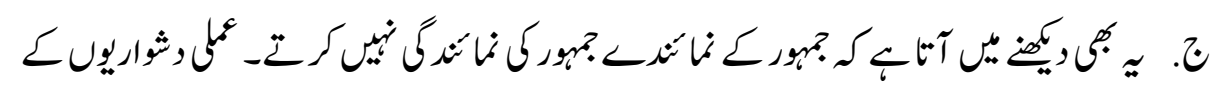

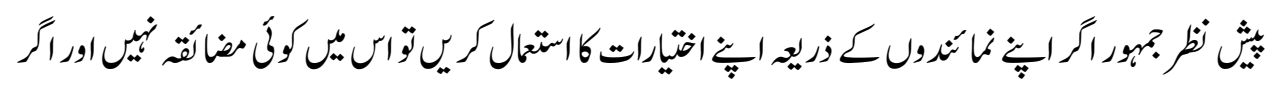

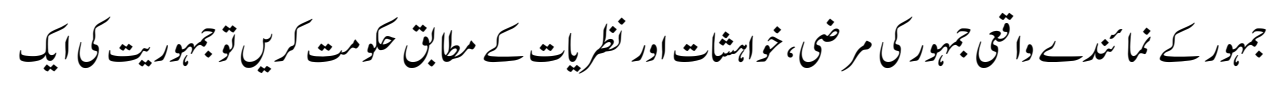

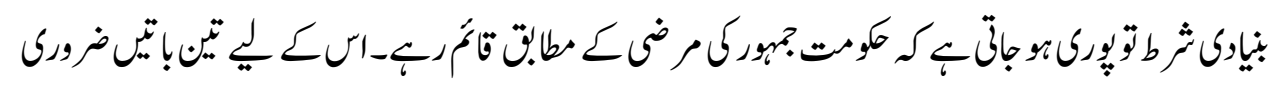

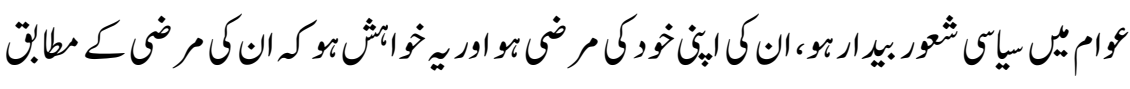

:

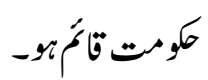

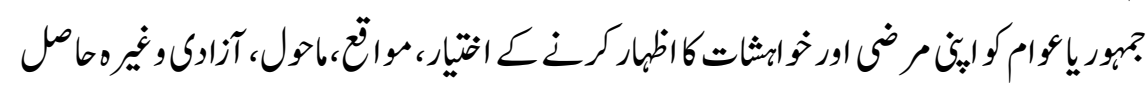

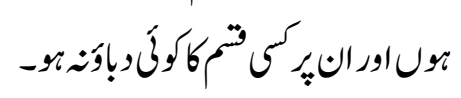

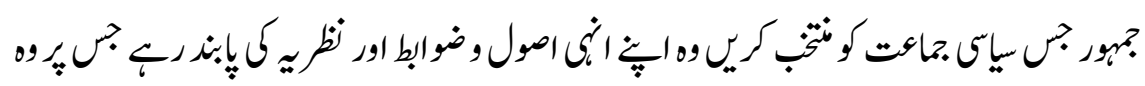

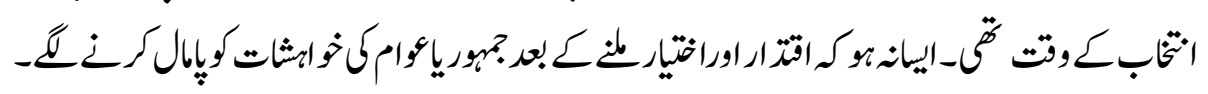

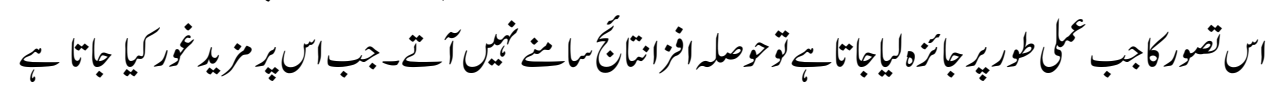

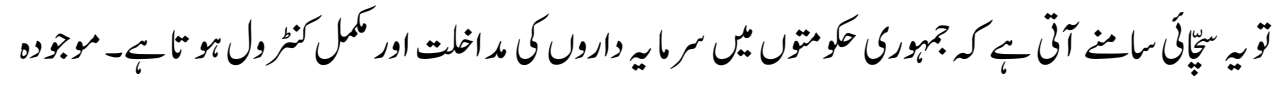

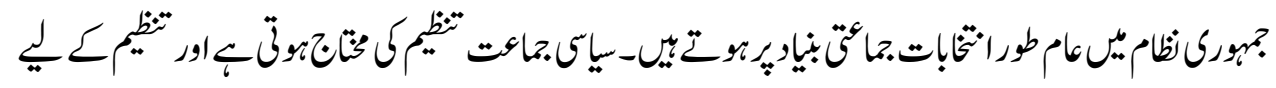

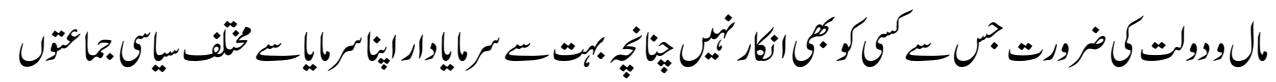

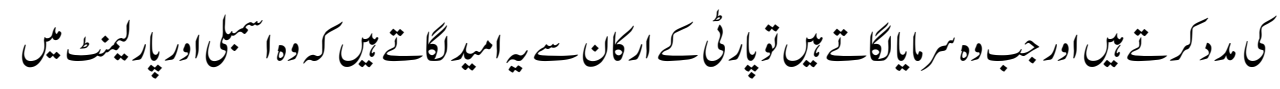

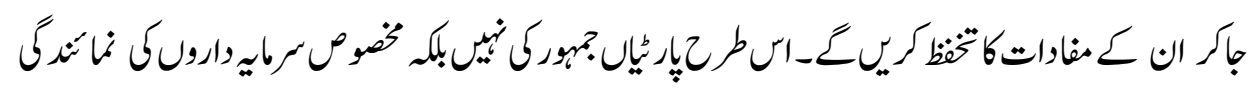




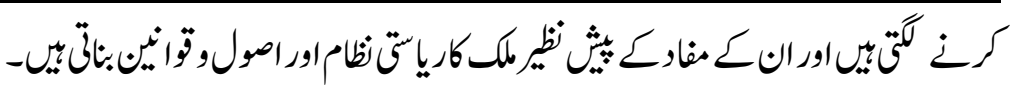

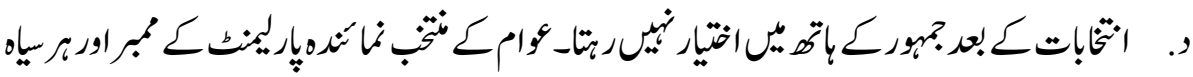

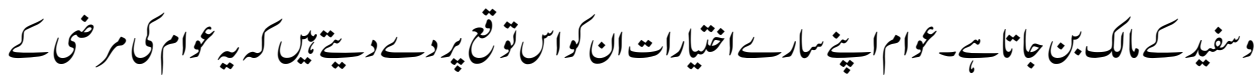

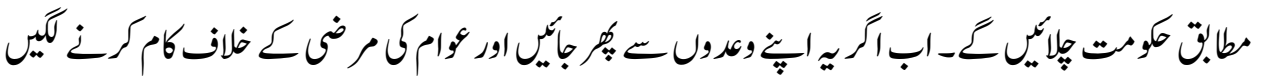

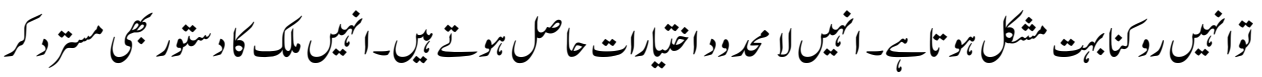

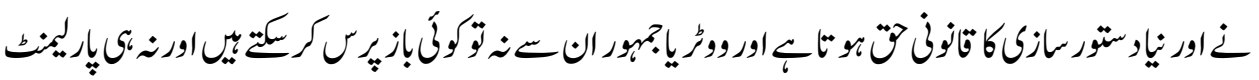

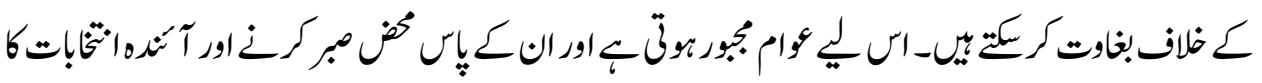

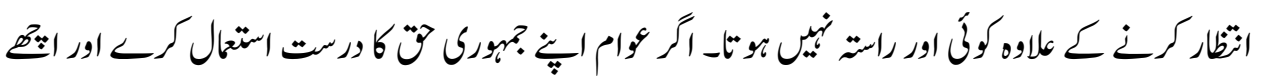

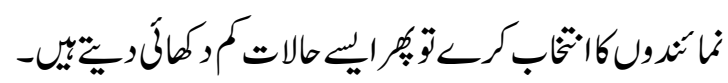

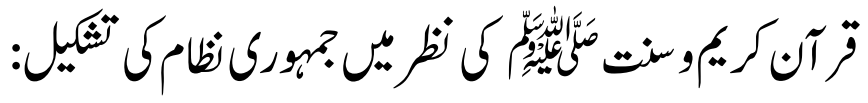

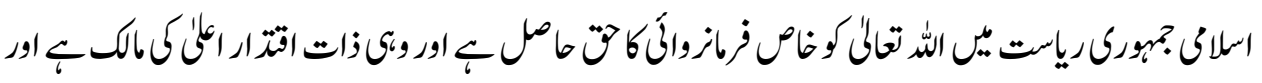

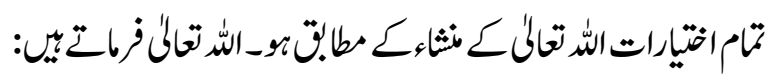

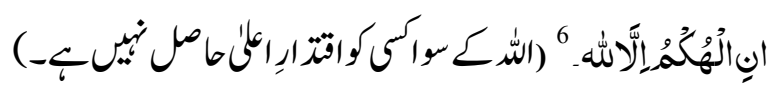

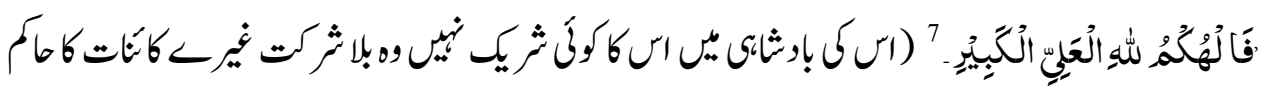

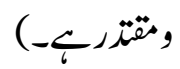

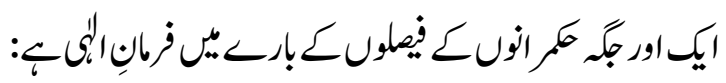

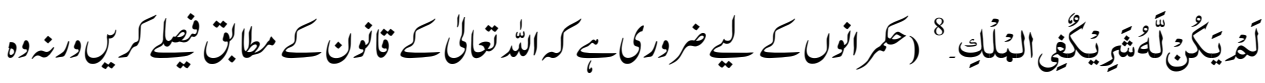

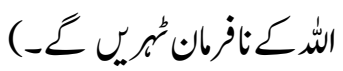

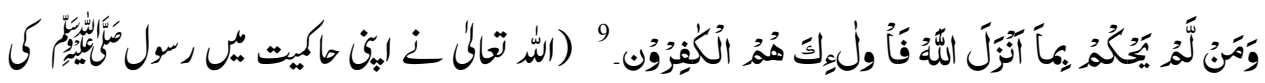

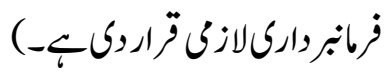

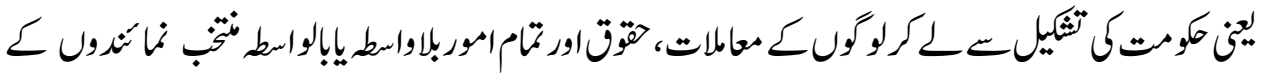

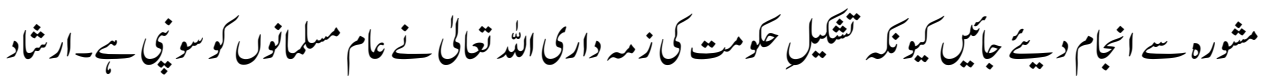
ربّأنج كم: 


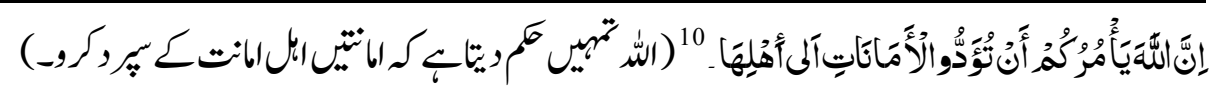

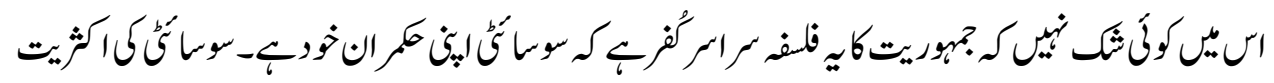

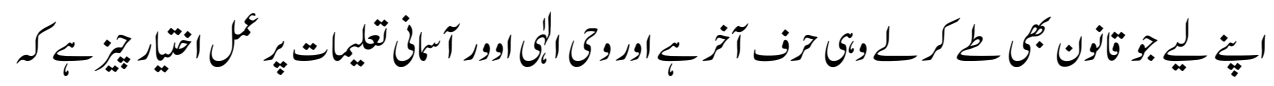

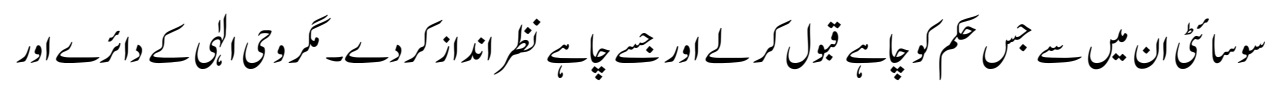

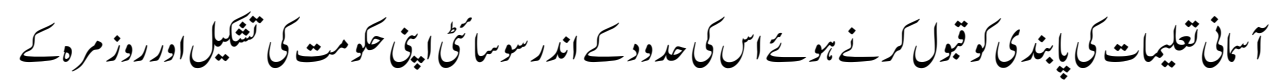

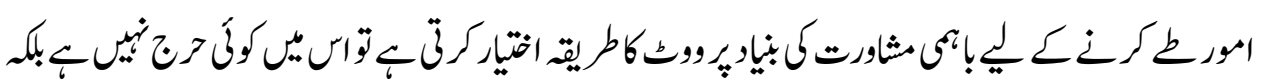

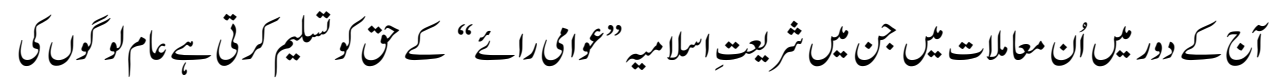

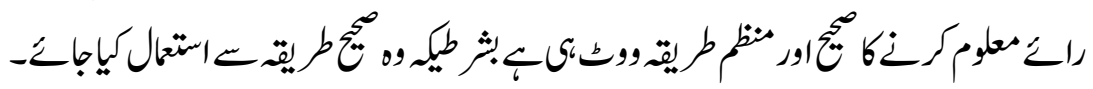

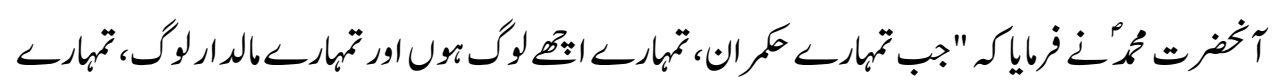

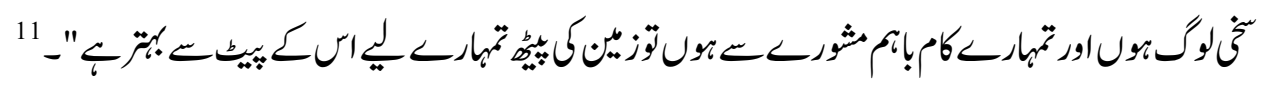

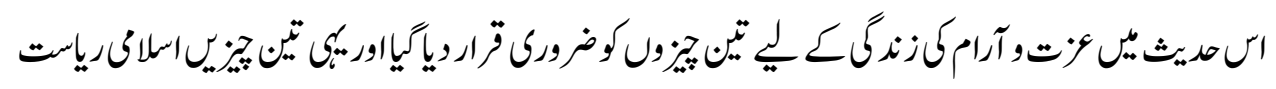

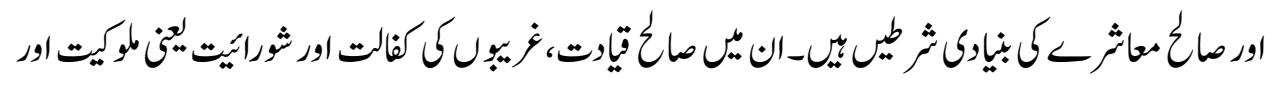

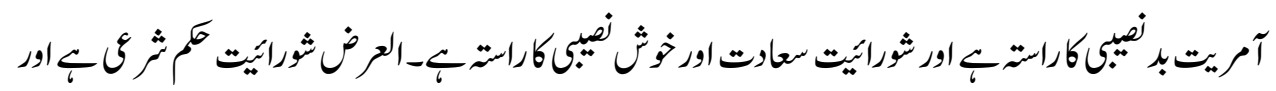

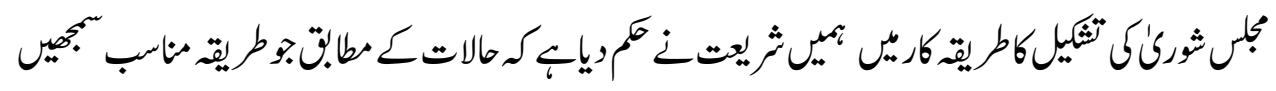

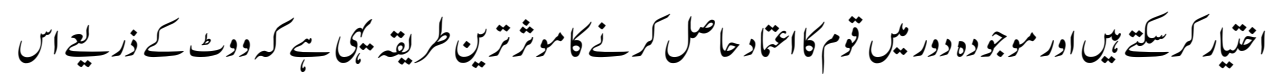

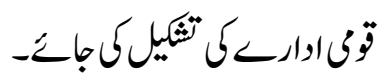

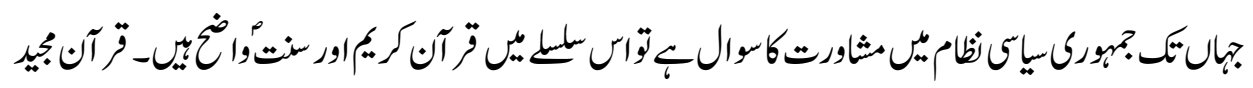

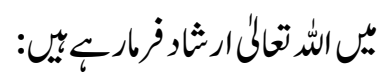

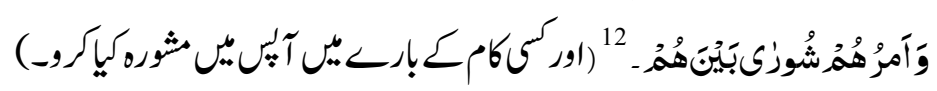

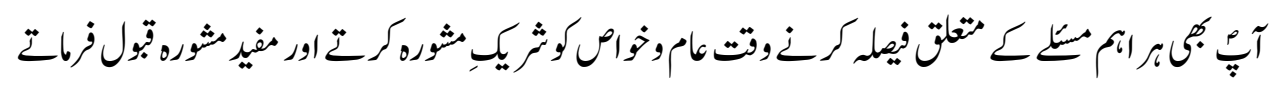

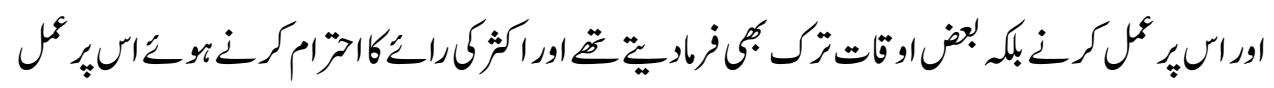

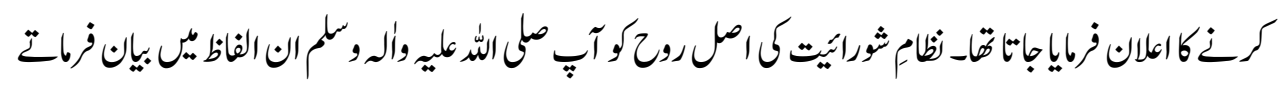

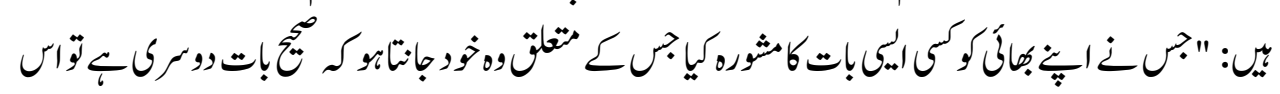

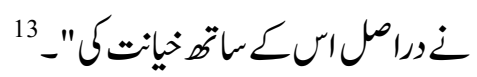




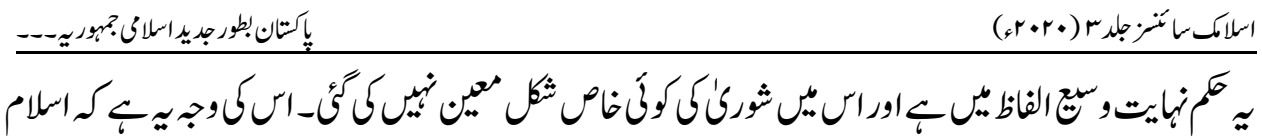

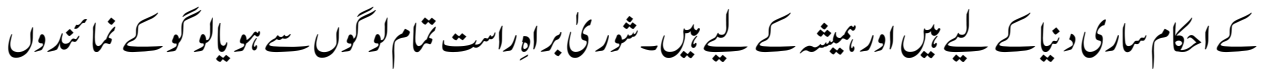

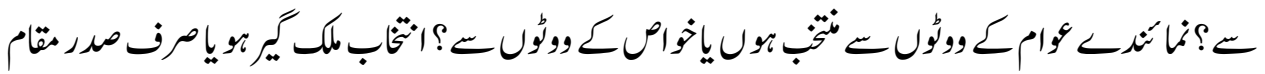

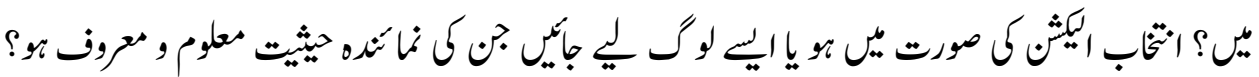

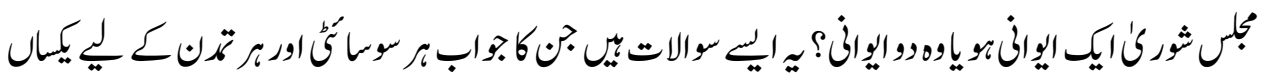

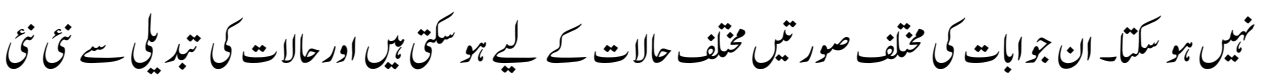

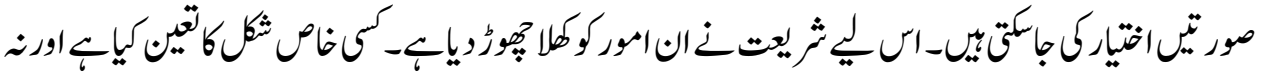

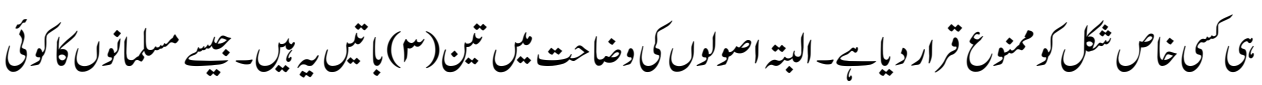

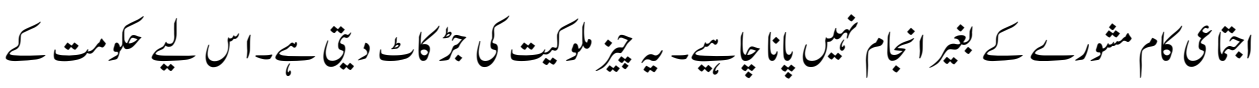

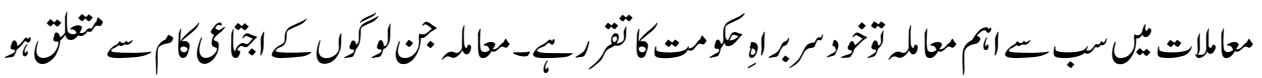

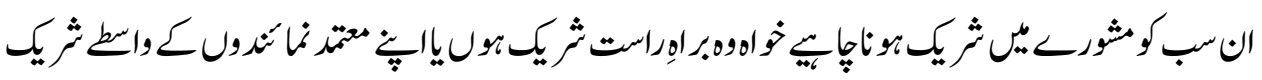

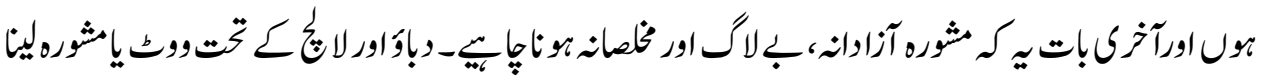

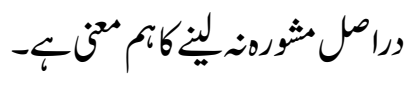

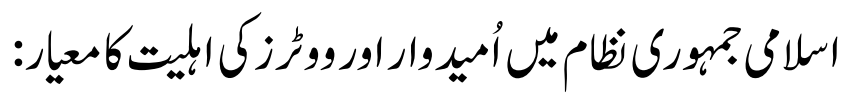

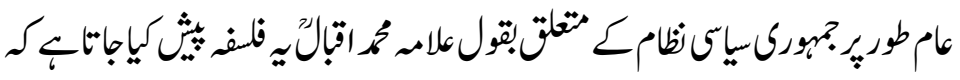

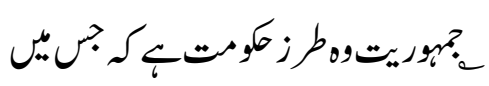

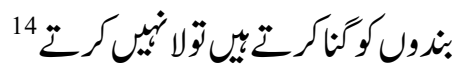

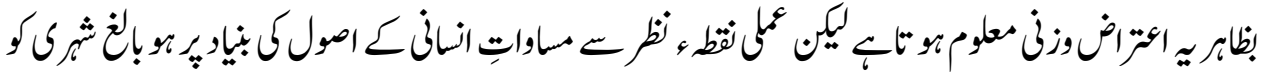

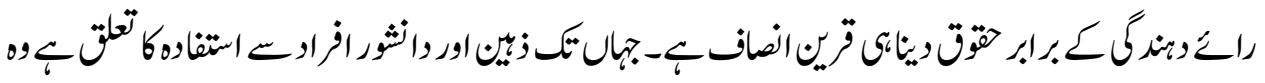

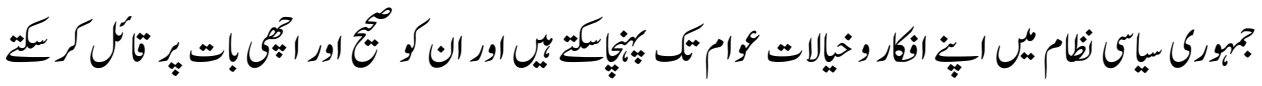

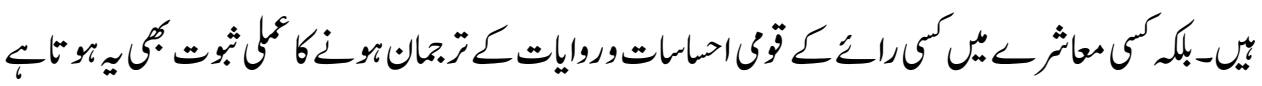

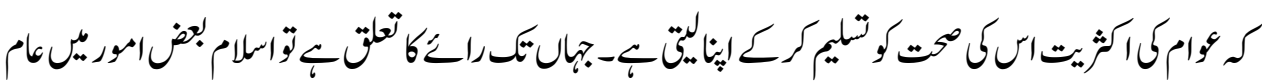

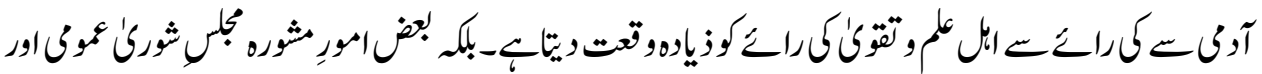




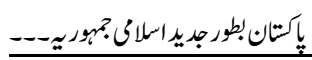

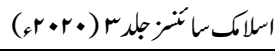

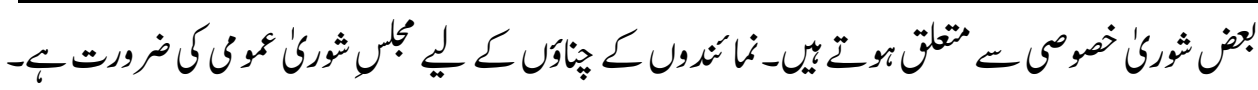

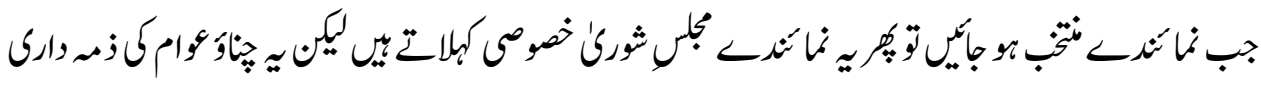

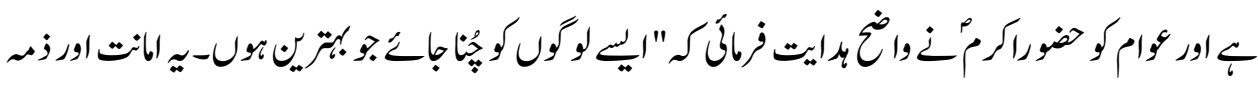

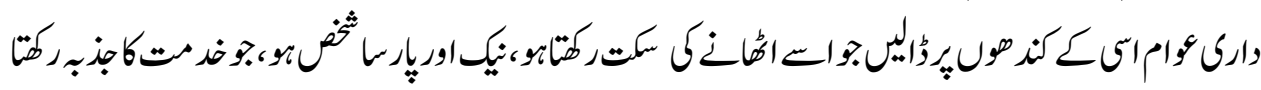

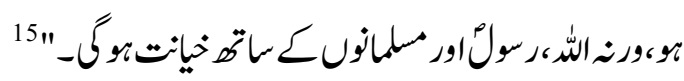

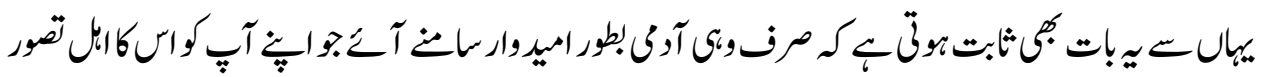

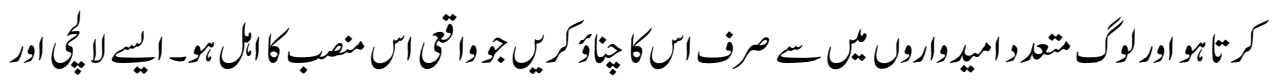

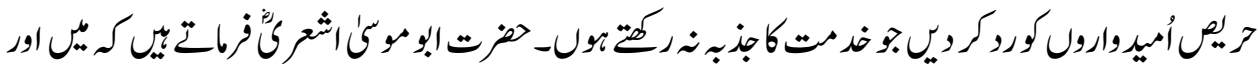

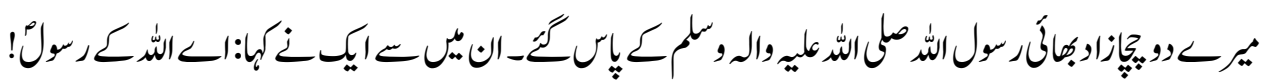

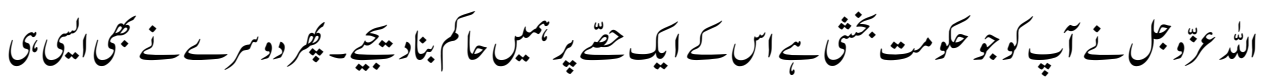

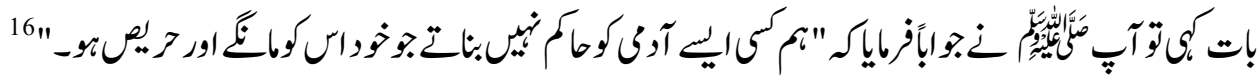

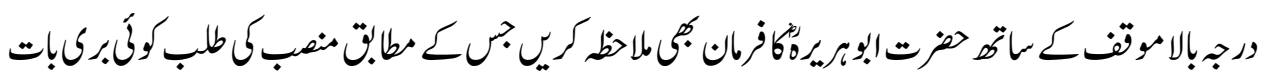

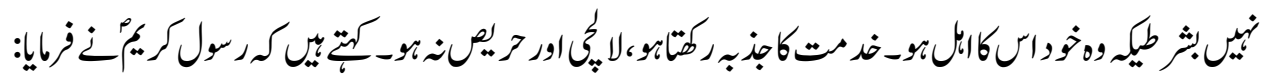

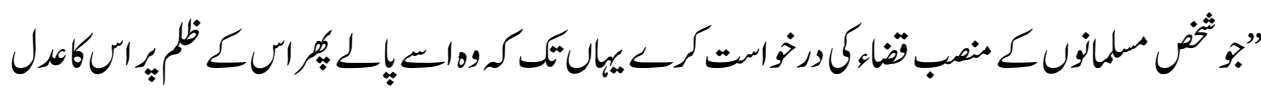

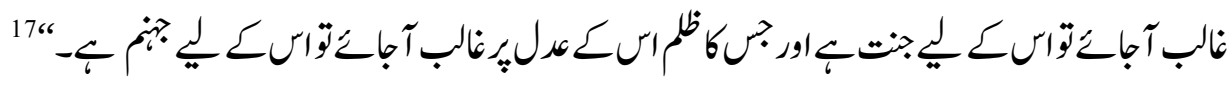

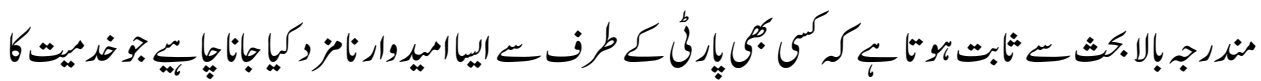

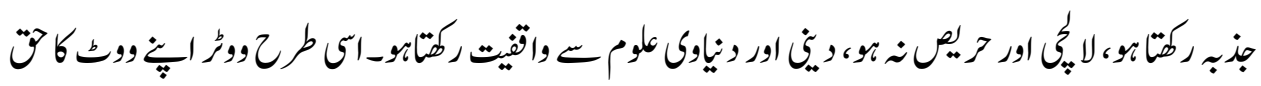

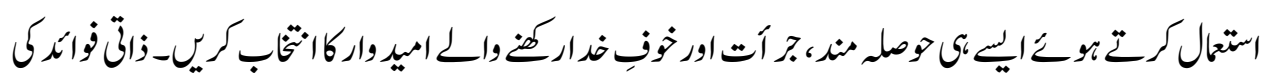

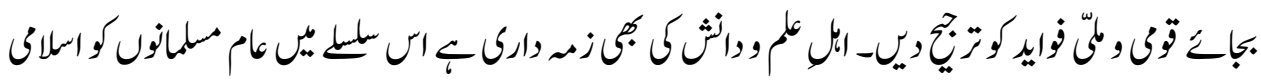

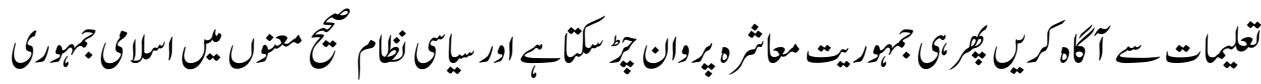

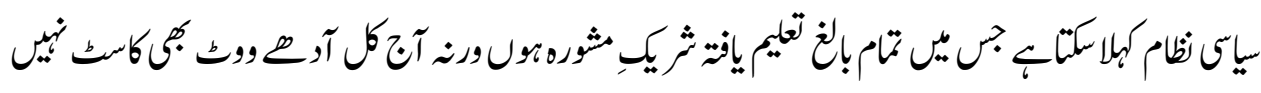

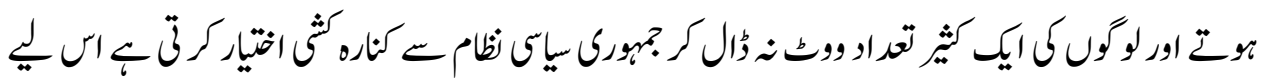

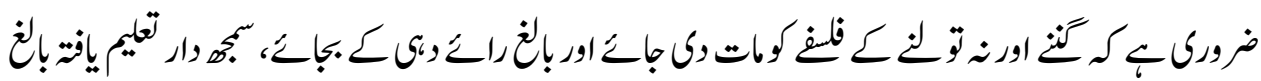

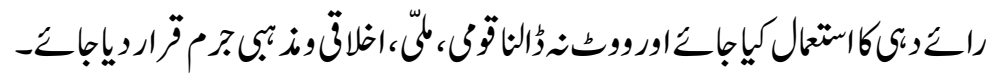

62 


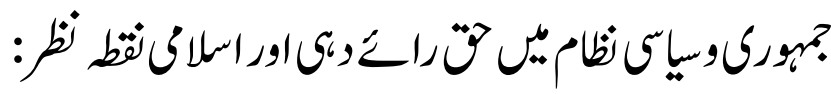

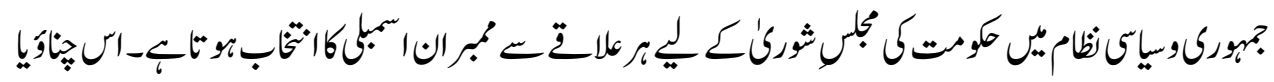

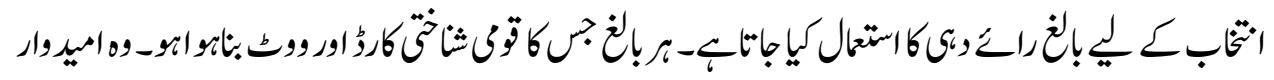

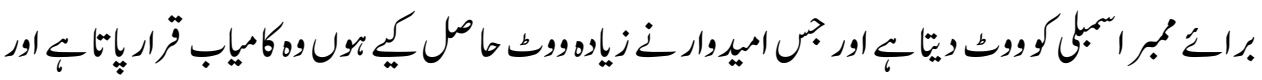

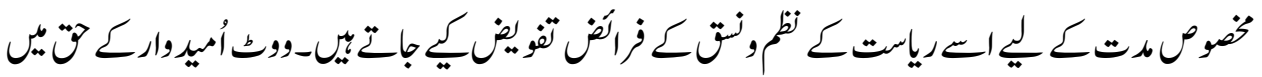

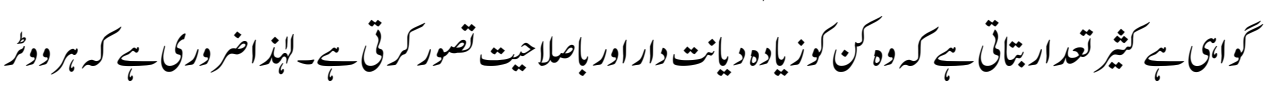

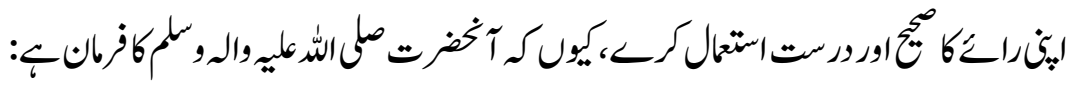

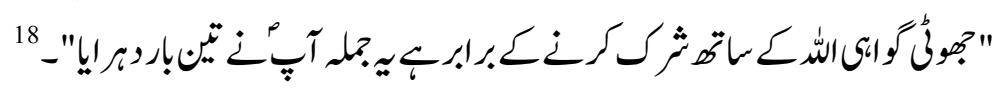

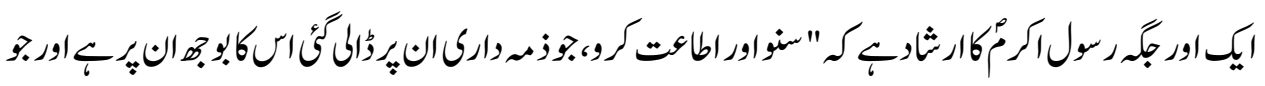

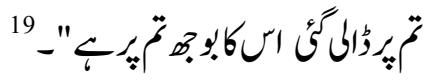

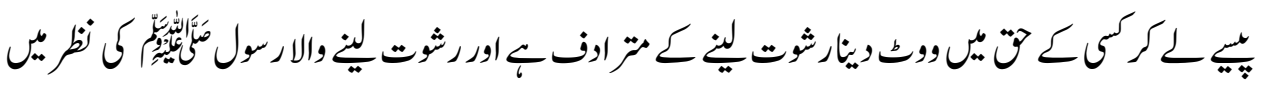

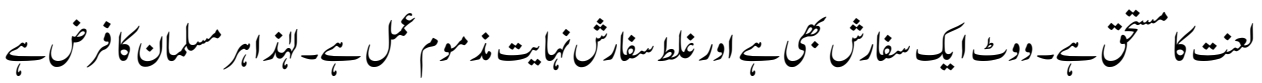

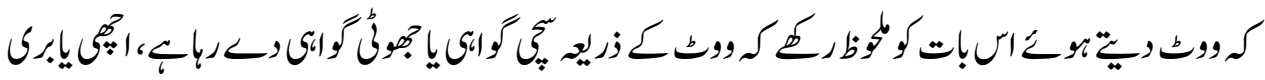

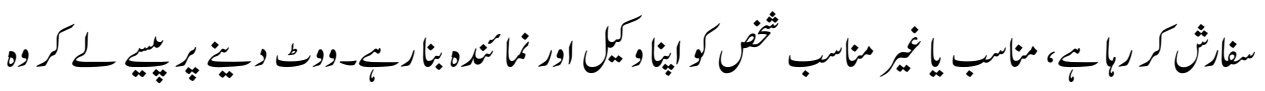

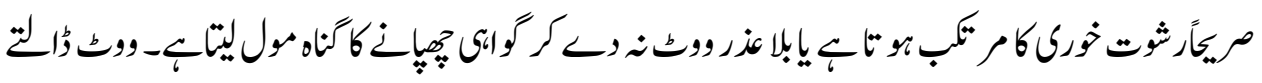

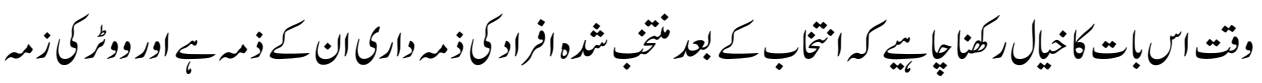

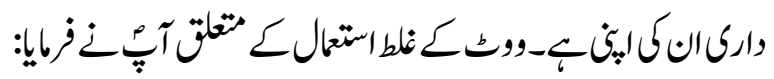

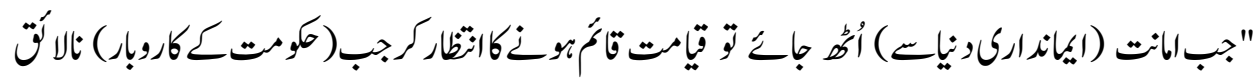

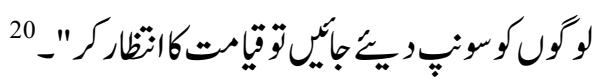

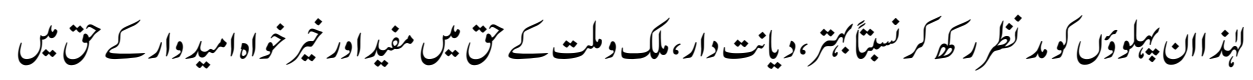

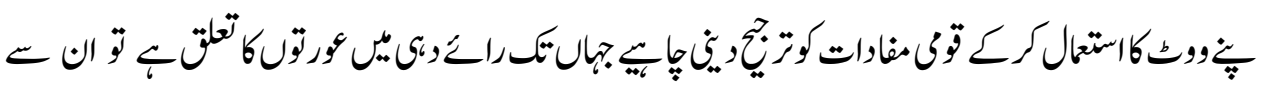

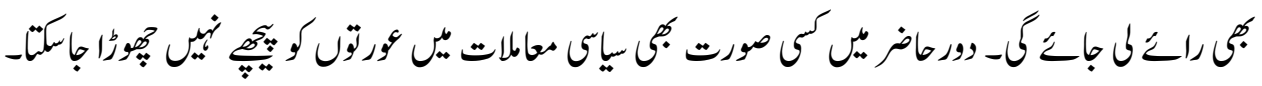
الشتقافزماتحيل: 


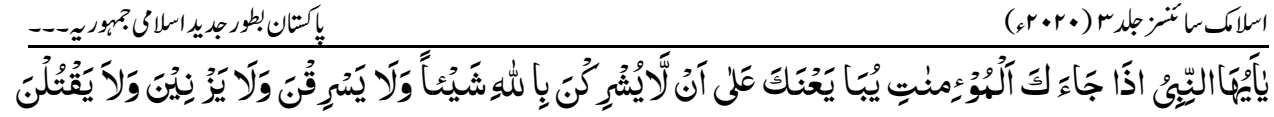

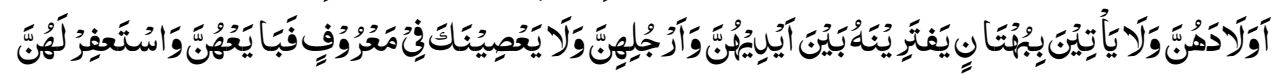

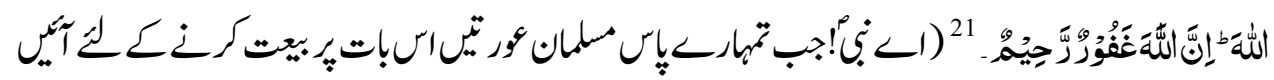

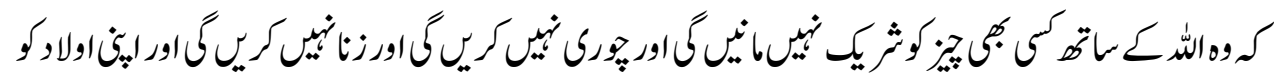

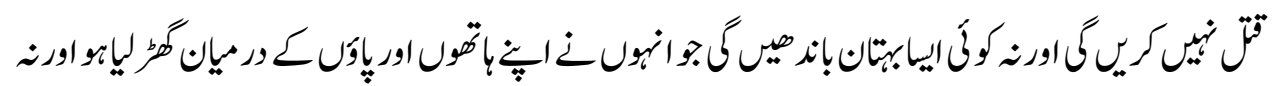

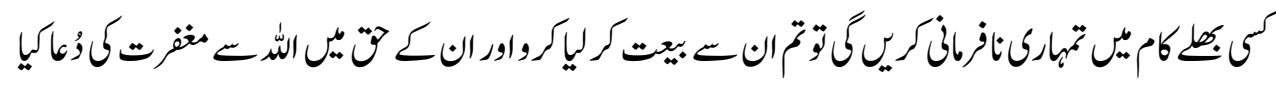

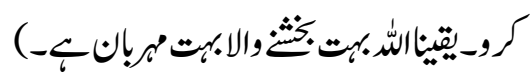

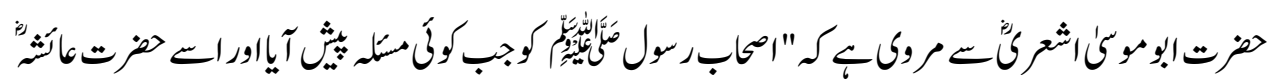

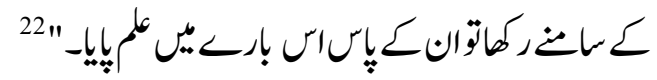

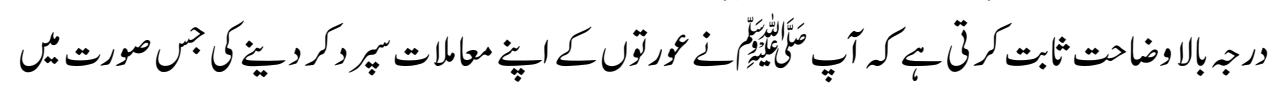

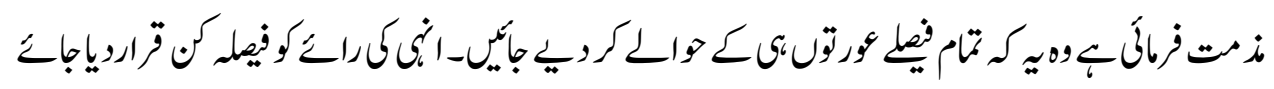

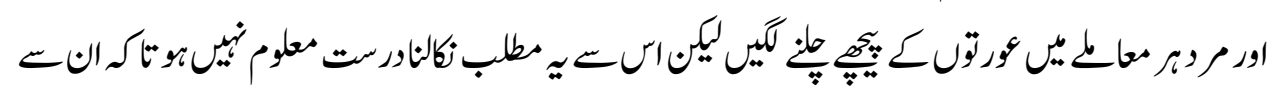

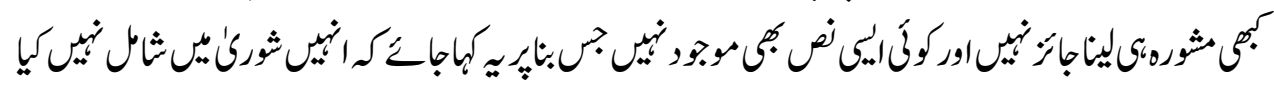

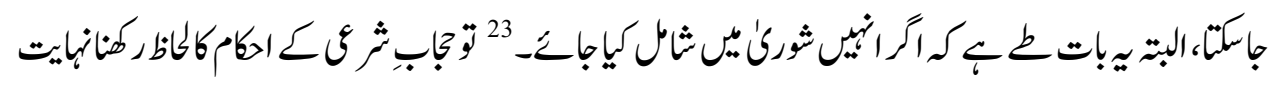

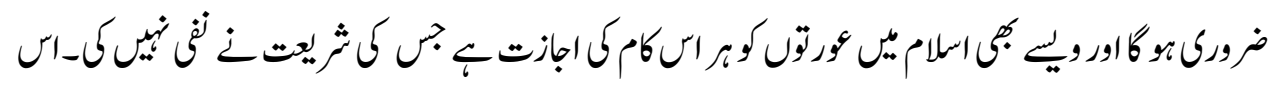

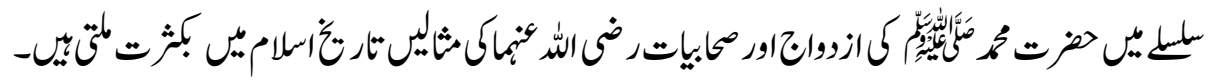

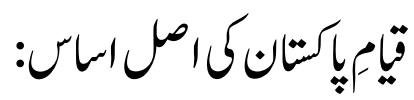

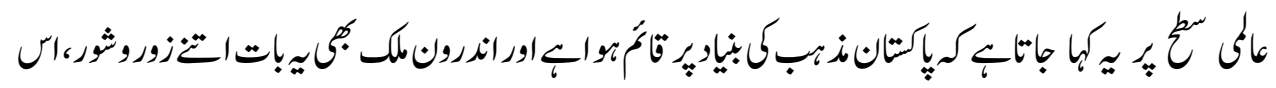

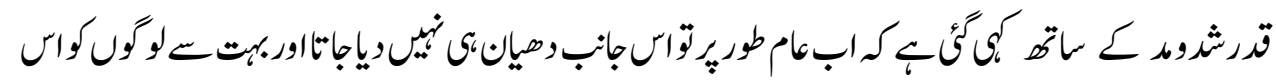

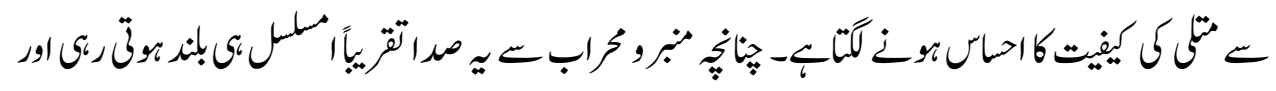

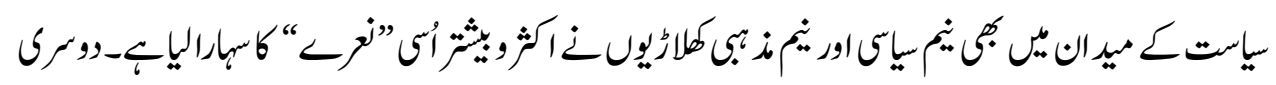

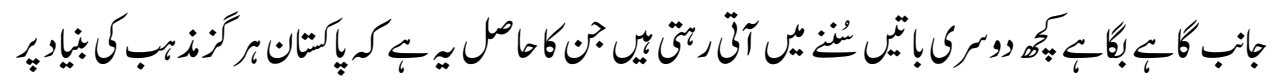

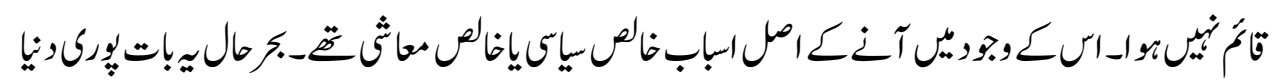

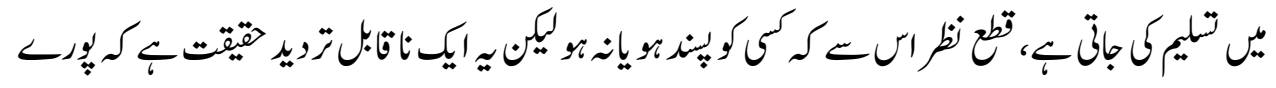




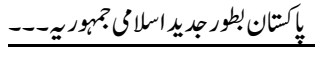

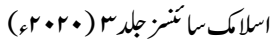

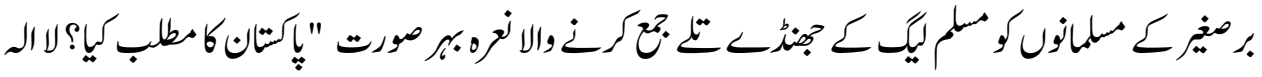

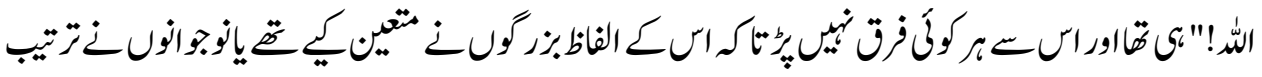

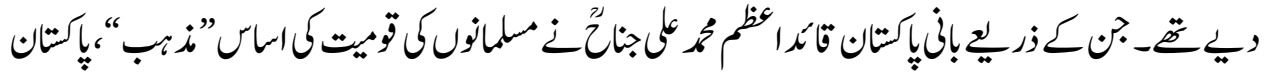

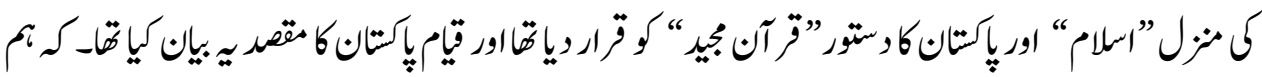

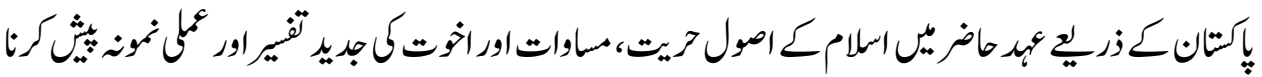

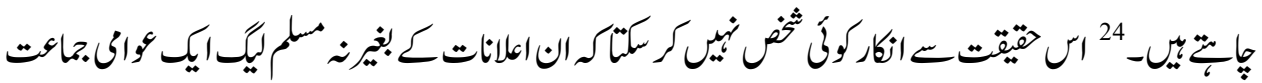

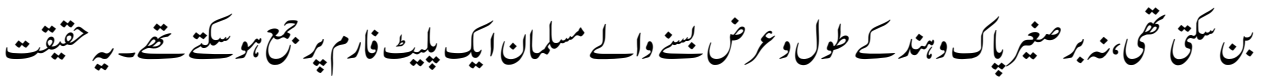

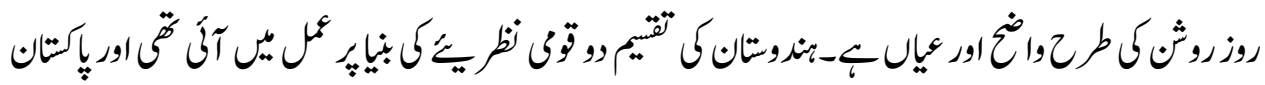

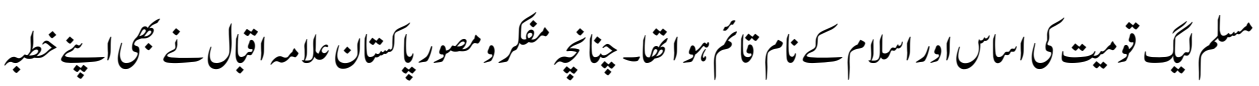

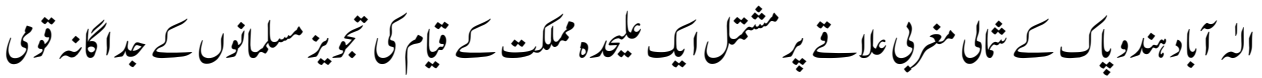

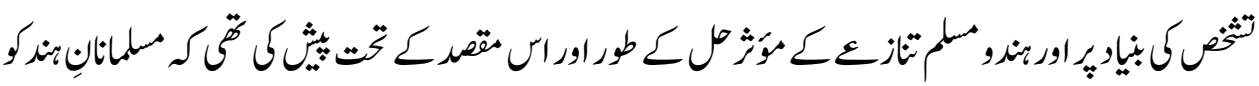

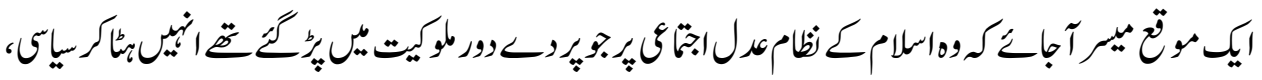

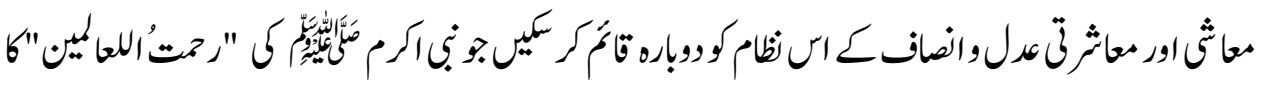

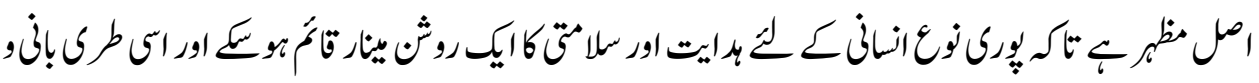

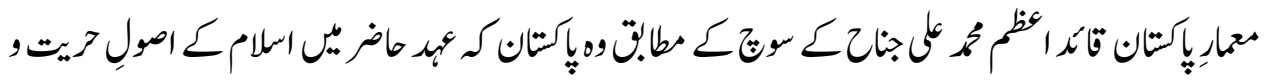

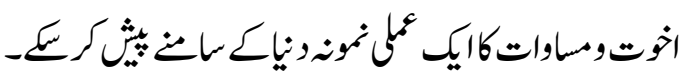

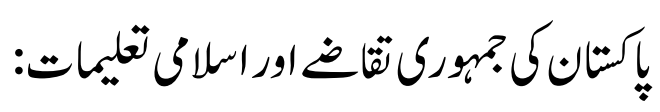

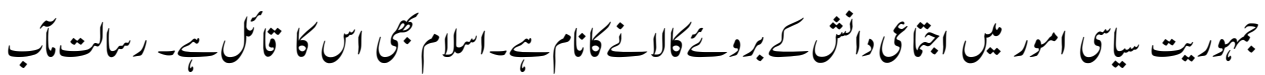

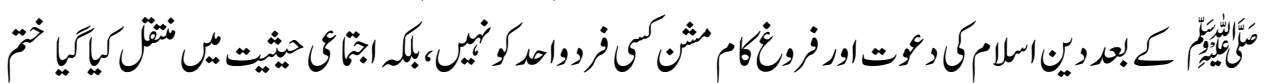

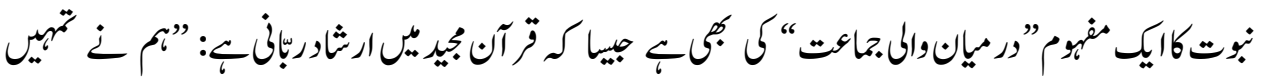

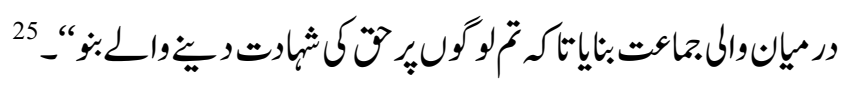

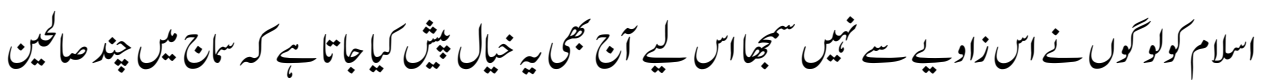

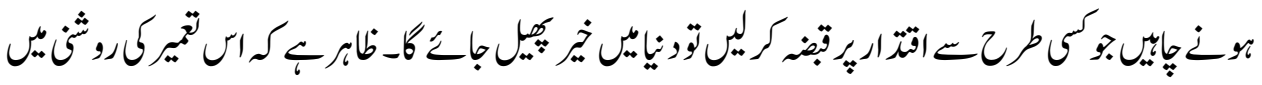




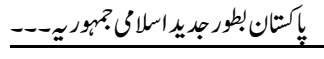

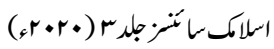

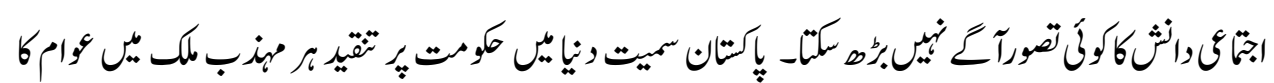

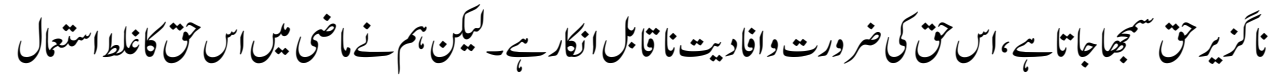

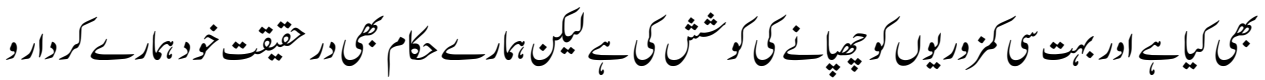

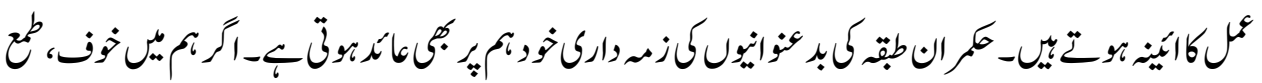

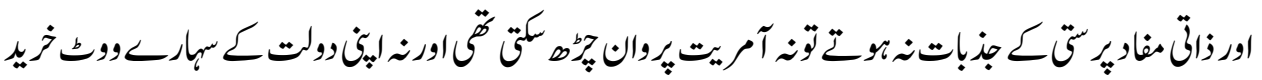

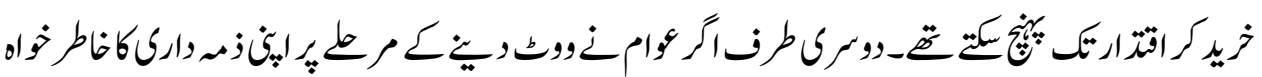

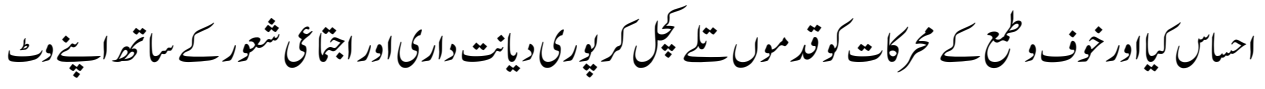

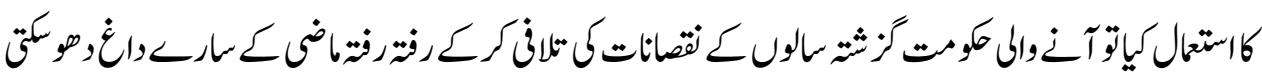

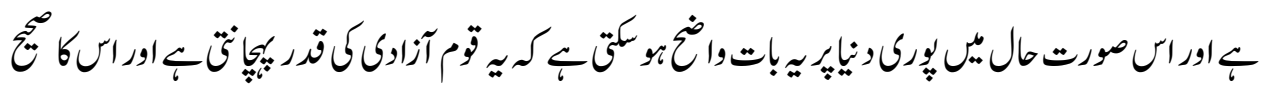

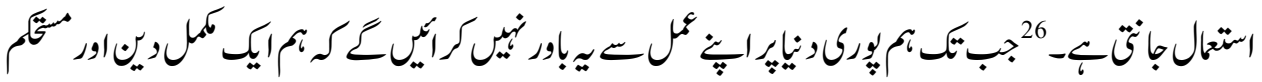

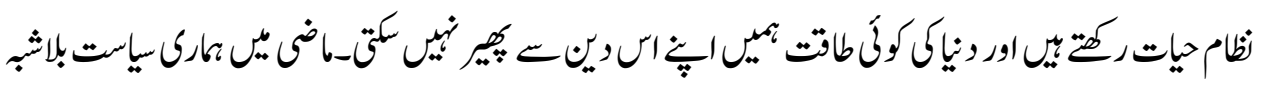

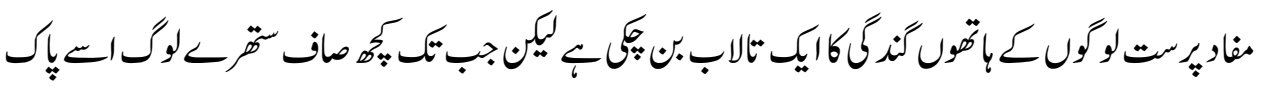

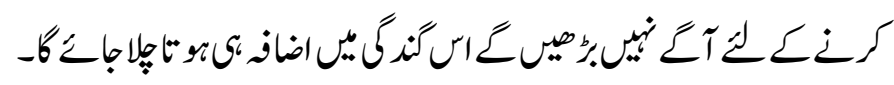

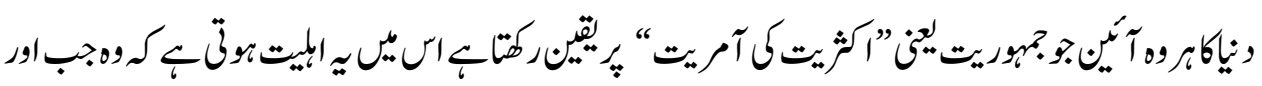

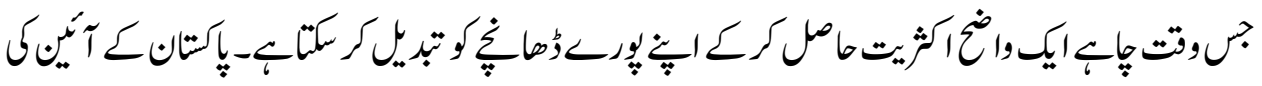

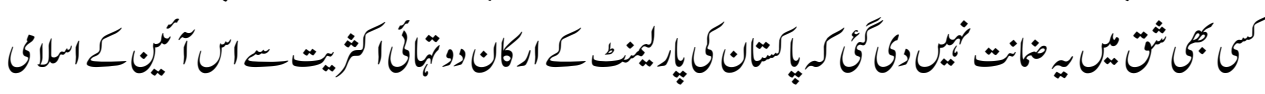

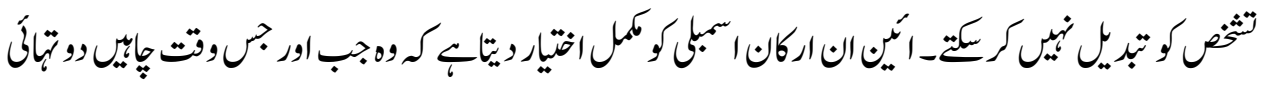

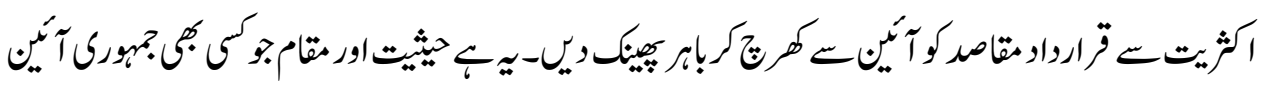

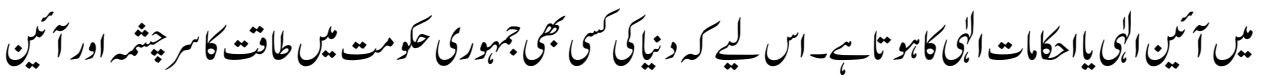

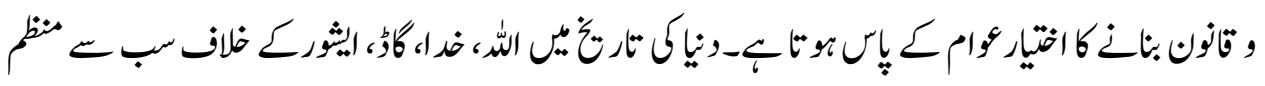

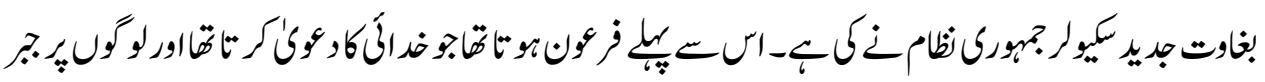

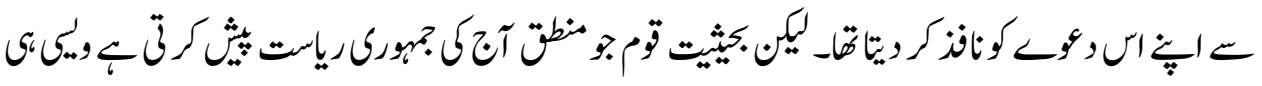

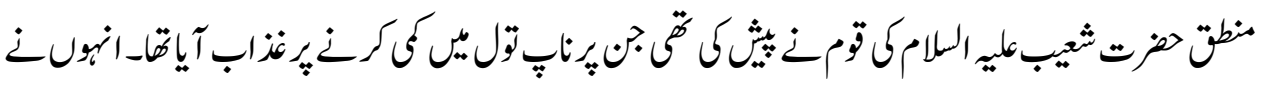

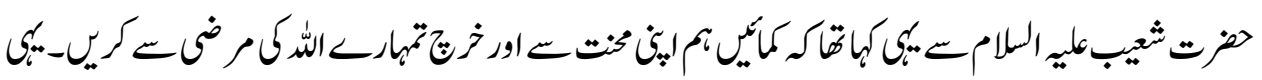




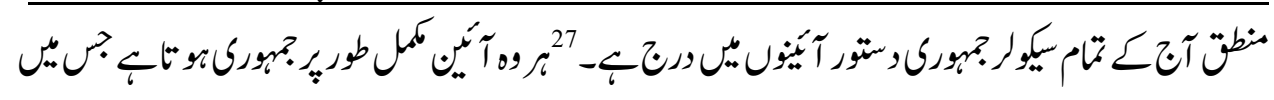

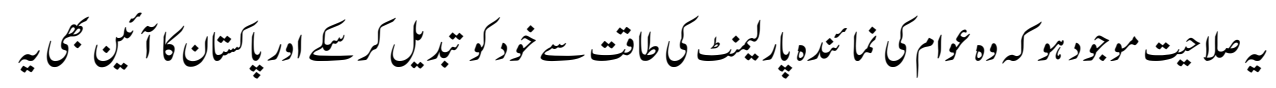

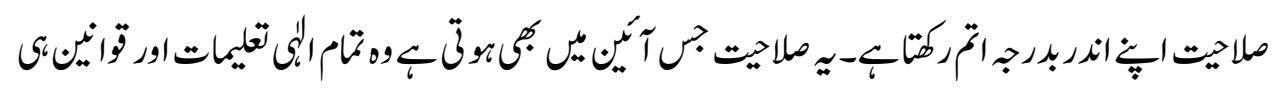

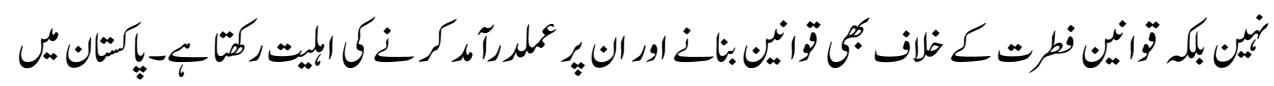

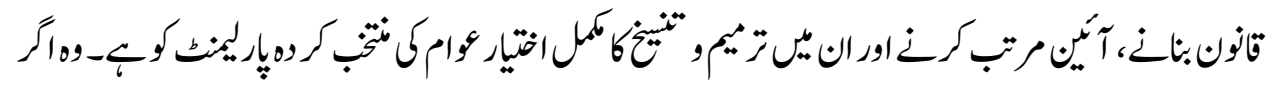

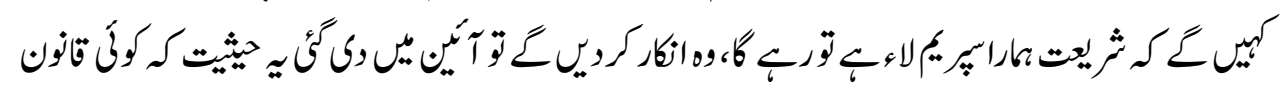

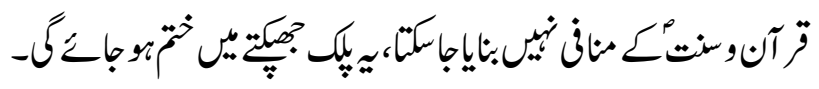

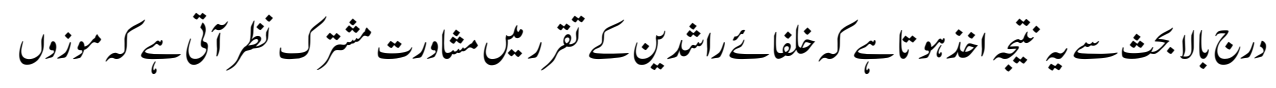

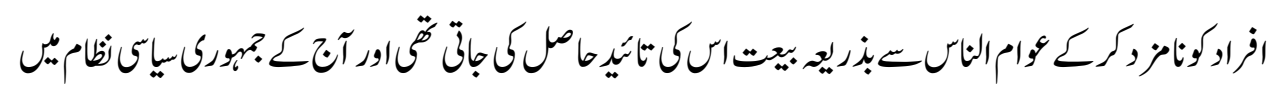

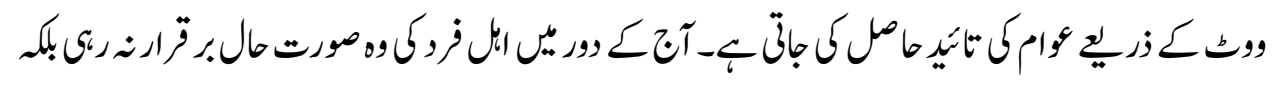

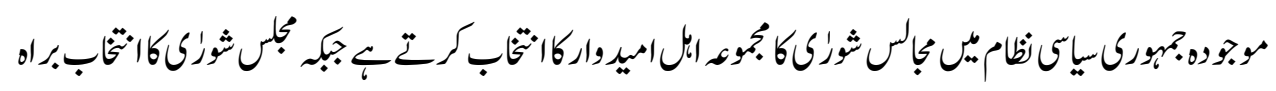

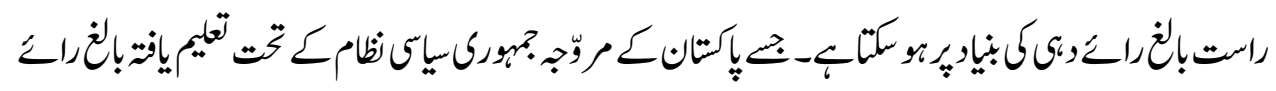

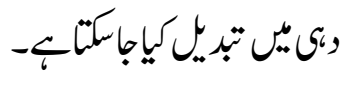

خلاصم.كث:

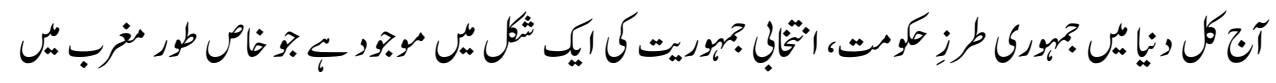

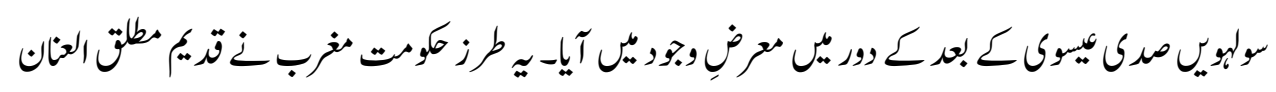

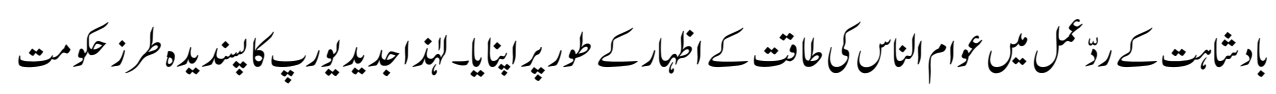

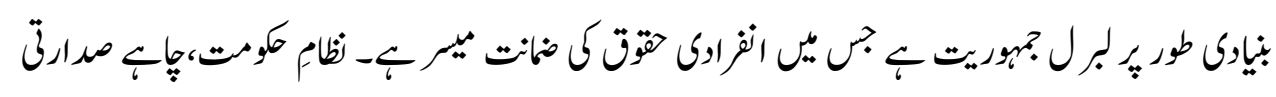

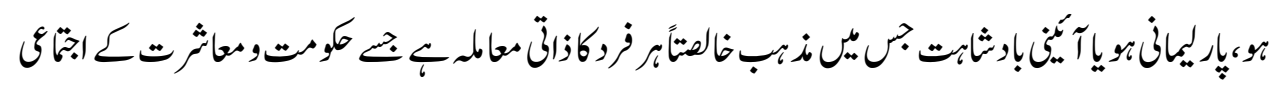

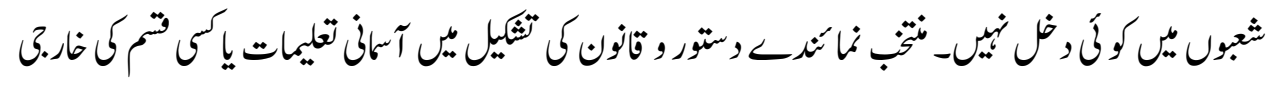

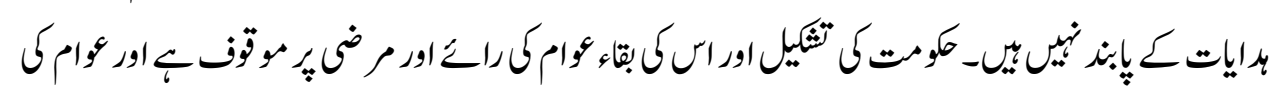

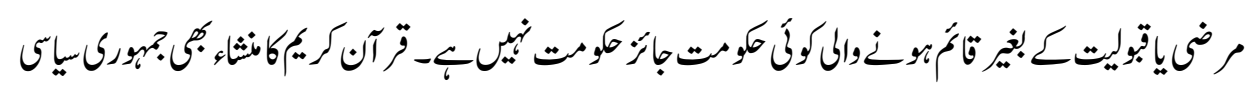

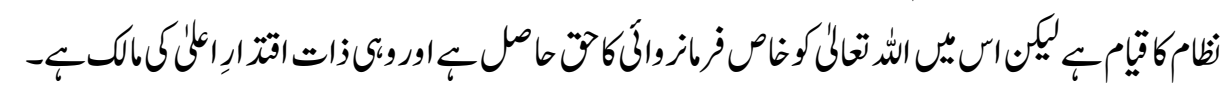




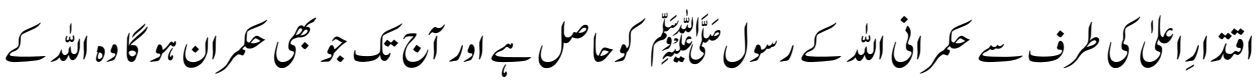

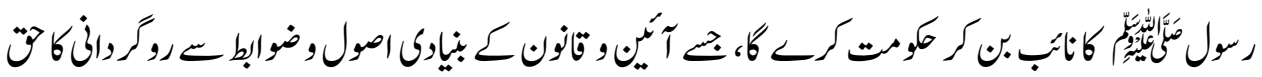

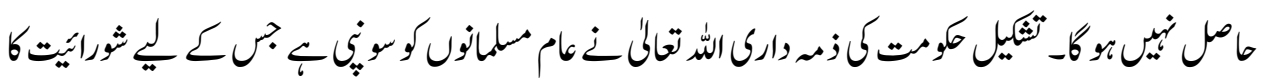

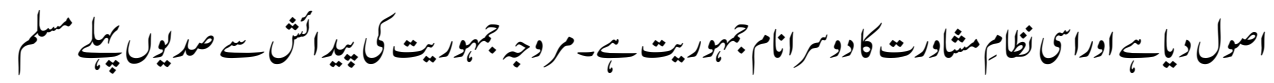

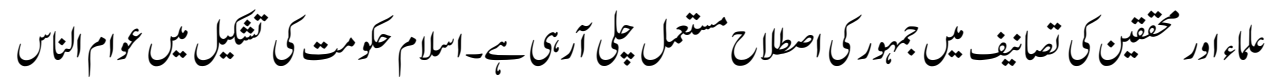

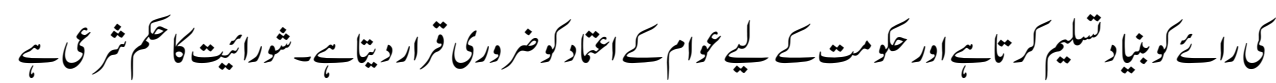

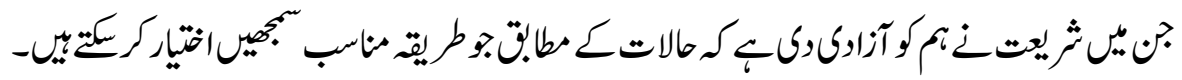

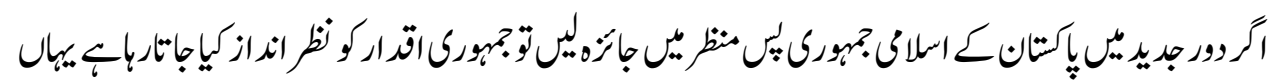

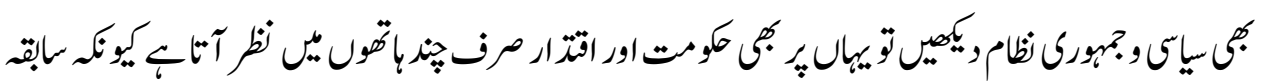

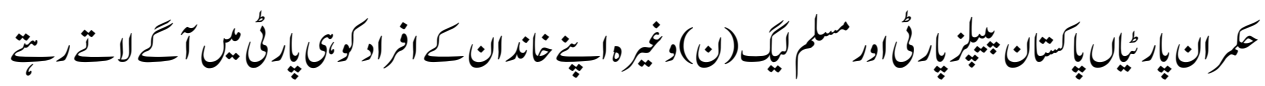

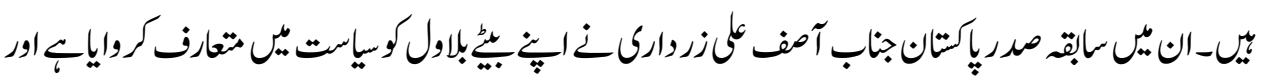

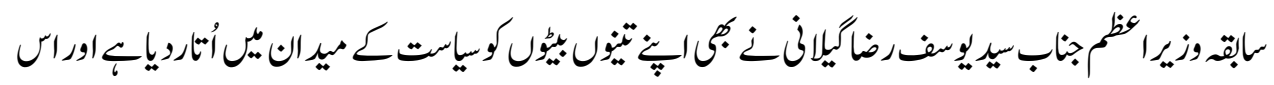

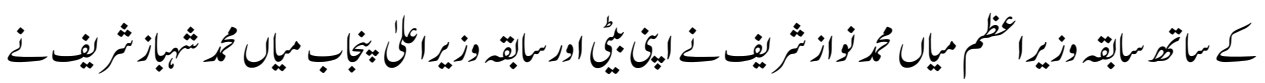

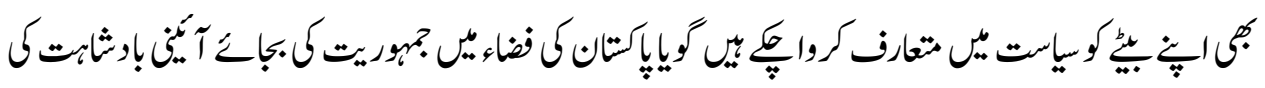

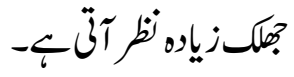

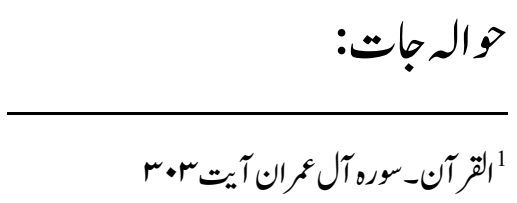

${ }^{2}$ Shan ul Haq Haqi, The Oxford English Urdu Dictionary, Karachi: Oxford University Press, 2007, p. 401

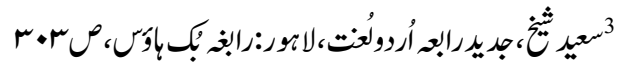

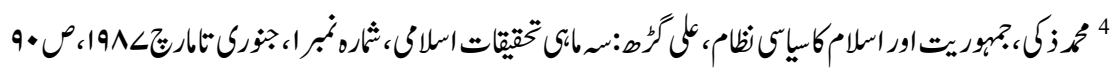

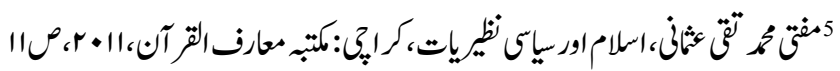

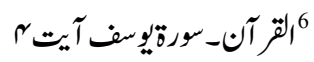




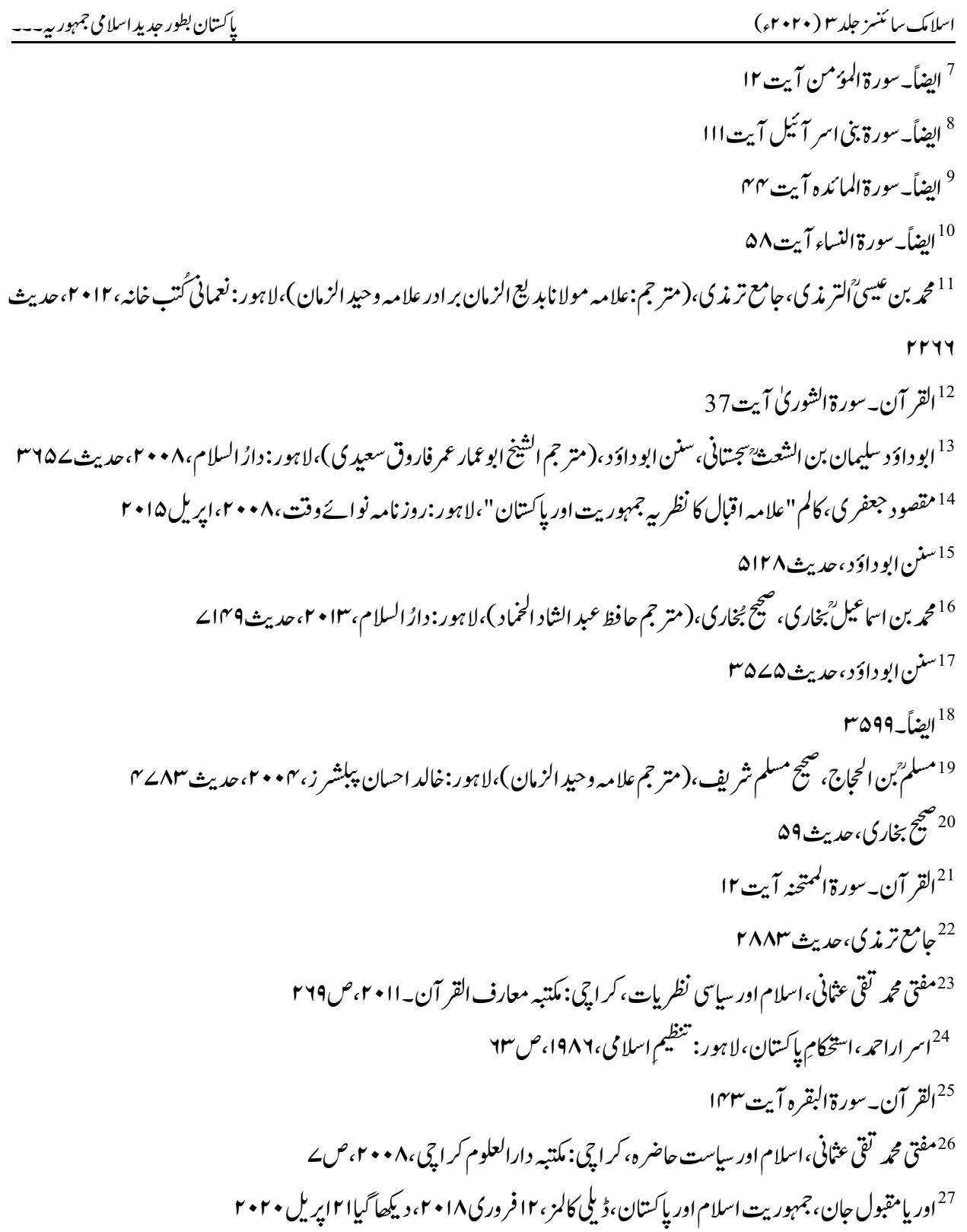

http://dailyurducolumns.com/column/orya-maqbool-jan/jamhoriat-islamaur-pakistan.aspx. 